\title{
Educative Mentoring: \\ Challenges and Enablers of Implementation in an Intermediate School Context
}

SARAH CATHERINE MARY PATTERSON

A thesis submitted in partial fulfilment of the requirements for the degree of Master of Education, Victoria University of Wellington. 


\begin{abstract}
An effective mentoring programme has a positive effect on the quality of teaching, student achievement, the retention of trained teachers and the teaching profession as a whole and the importance of mentoring beginning teachers cannot be overstated. Recently, there has been a shift in thinking on the most effective way to mentor beginning teachers. This shift has been away from a mentoring approach that only provides support and guidance towards educative mentoring which both challenges and transforms teaching practice and is based on a co-constructed learning relationship. In 2012, the New Zealand Teachers Council introduced guidelines into schools to assist mentor teachers in the educative mentoring of beginning teachers. The purpose of this case study was to examine how effectively one intermediate school was implementing these guidelines, identify challenges involved in the implementation process and describe the conditions necessary to support effective, educative mentoring. To answer the research questions, data was collected through an on-line survey, focus groups and an interview. The findings indicated that while both the mentors and beginning teachers felt that the guidelines were being implemented, neither group believed the mentoring process at the school was particularly effective. The biggest challenge to the implementation of the guidelines was differing perceptions of the purpose and potential of a mentoring programme. The beginning teachers, mentor teachers and principal all held differing views on the purpose of mentoring, leading to other challenges including the lack of clarity around procedures and expectations and tension between assistance and assessment.
\end{abstract}




\section{Acknowledgements}

I would like to acknowledge and thank:

- The Ministry of Education for the study grant that allowed for the writing of this thesis.

- My supervisors Kate Thornton and Brenda Service whose 'Coaching and Mentoring' paper first got me interested in the subject.

- My school and principal, for allowing the study to take place.

- My mother-in-law for flying over from England to look after my daughter who was born in April of the year this research was completed. 


\section{Contents}

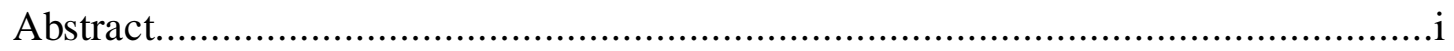

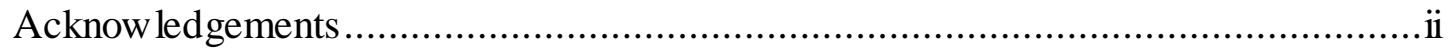

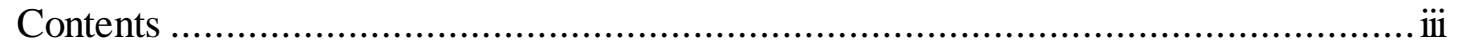

\section{Chapter One: Introduction}

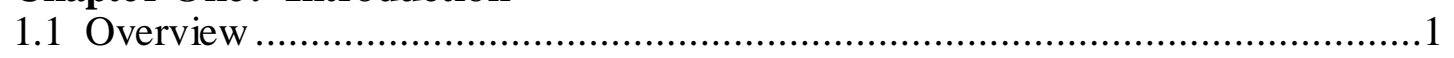

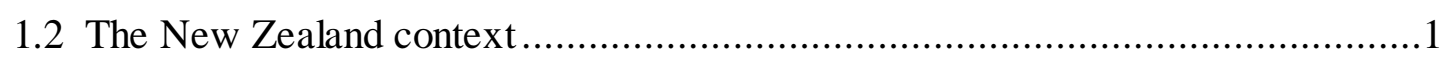

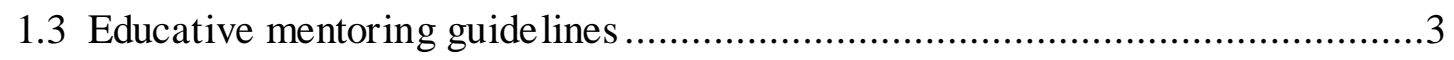

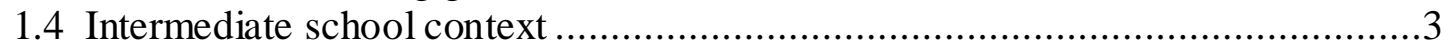

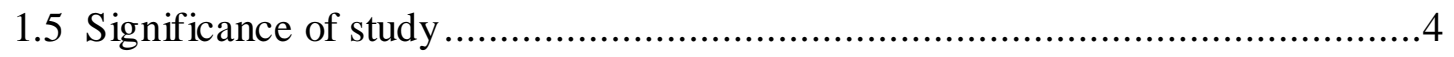

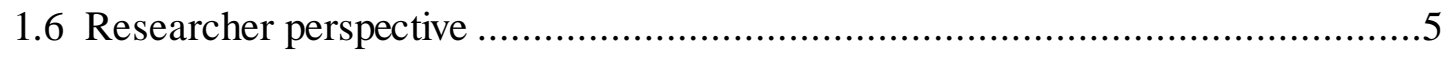

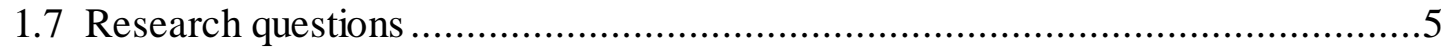

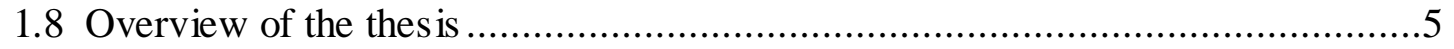

\section{Chapter Two: Lite rature Review}

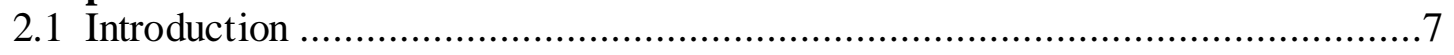

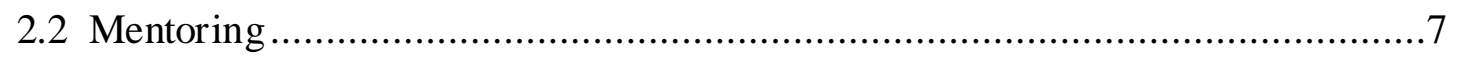

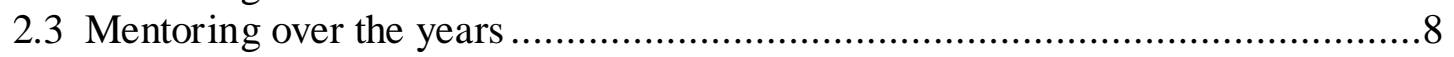

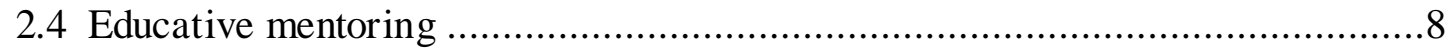

2.5 Components of an effective mentoring programme .......................................9

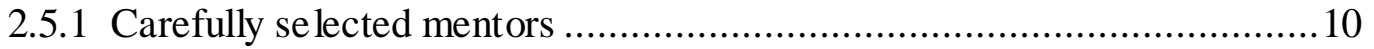

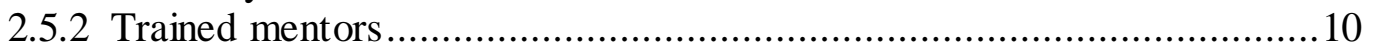

2.5.3 Programme structure ................................................................. 11

2.5.4 Based in a community of support...................................................11

2.6 The benefits of an effective mentoring programme ....................................... 12

2.6.1 Improvement in teacher quality and student achievement .....................12

2.6.2 Reduction in attrition of trained teachers........................................... 13

2.6.3 Increase in mentor capabilities........................................................... 14

2.6.4 Development of the teaching profession .......................................... 14

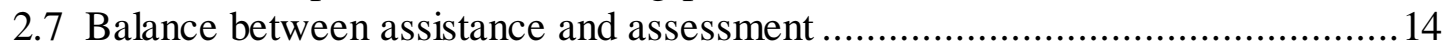

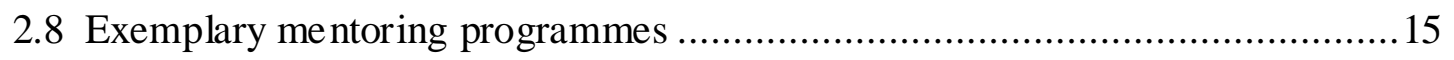

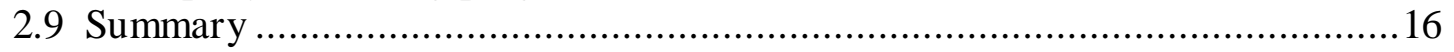

\section{Chapter Three: Methodology}

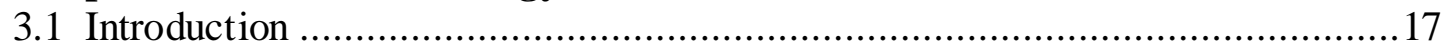

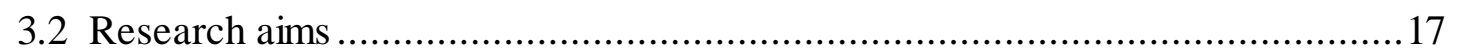

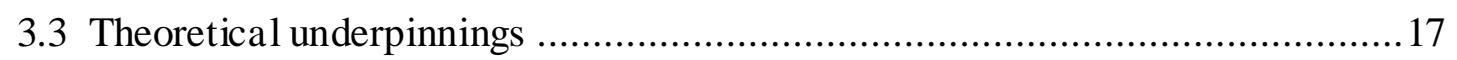

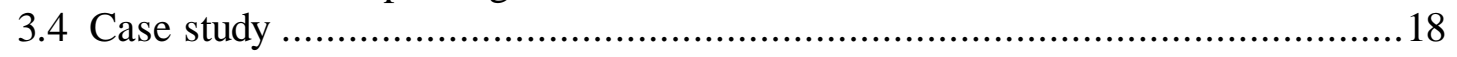

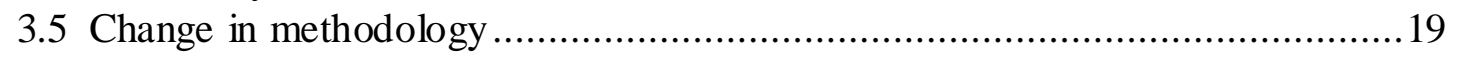

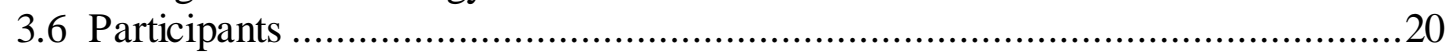

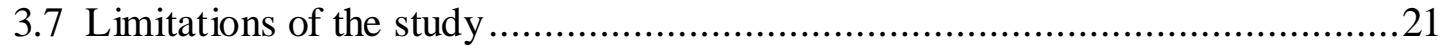

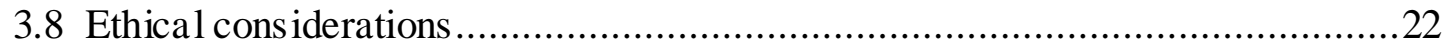

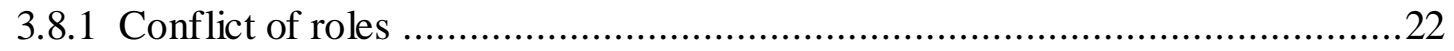

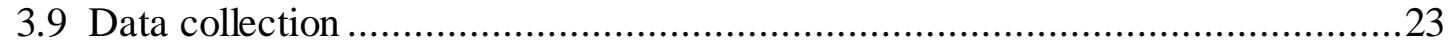

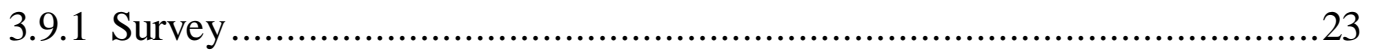

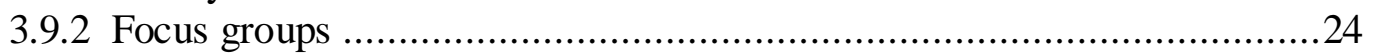

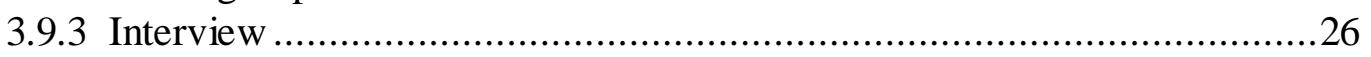

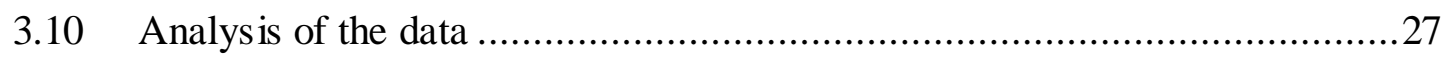




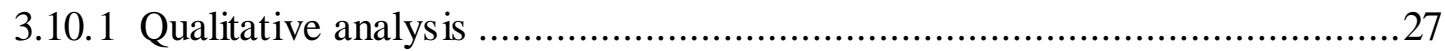

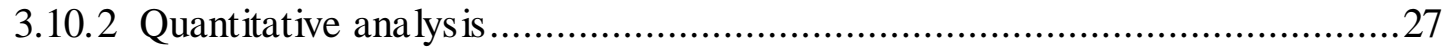

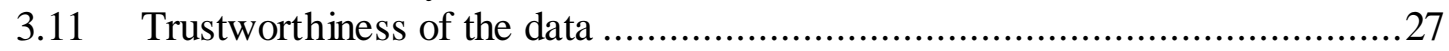

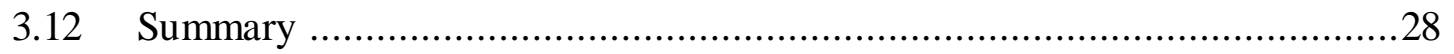

\section{Chapter Four: Findings}

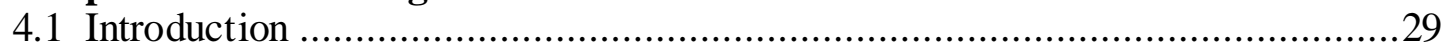

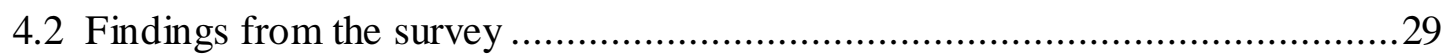

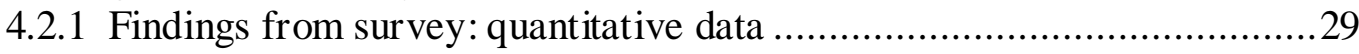

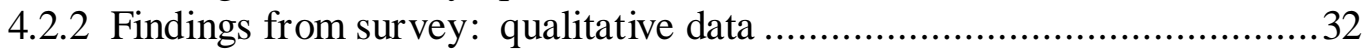

4.3 Findings from the mentor teachers focus group ..........................................33

4.3.1 Positive relationships between mentors and PRTs ...............................33

4.3.2 Challenges to an effective mentoring programme................................33

4.3.3 Enablers to an effective mentoring programme ....................................36

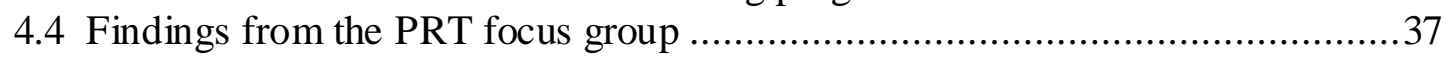

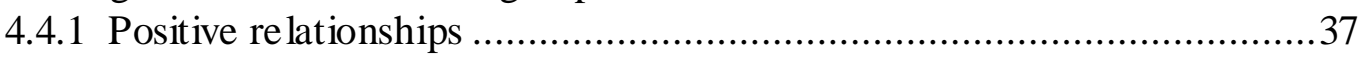

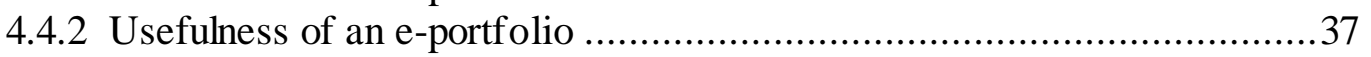

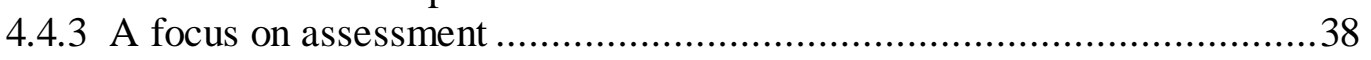

4.4.4 Mentor selection and clarity of process ...............................................3

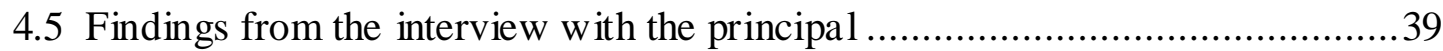

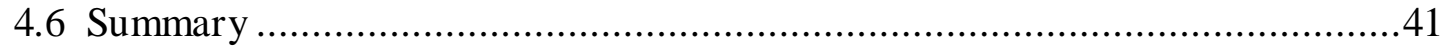

\section{Chapter Five: Discussion}

5.1 Introduction ....

5.2 What are the challenges of mentoring beginning teachers in an intermediate context?

5.2.1 Differences in vision of mentoring purpose ......................................4 43

5.2.2 Unclear procedures ...............................................................4

5.2.3 Lack of effective mentoring process ..........................................44

5.2.4 Untrained mentors ..........................................................................45

5.3 What needs to happen to enable effective mentoring to occur? ......................45

5.3.1 Communication of the purpose of mentoring.....................................45

5.3.2 Leadership of the mentoring programme.........................................48

5.3.3 Effective mentor selection process................................................49

5.3.4 Ongoing professional development for mentors ................................50

5.3.5 Based in a community of support....................................................51

5.4 How does the tension between assistance and assessment affect the mentoring

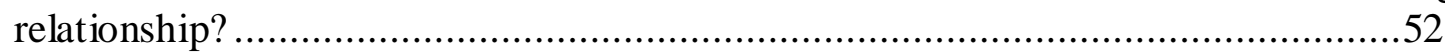

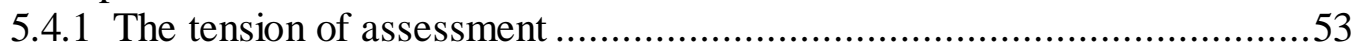

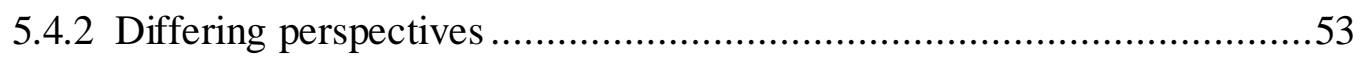

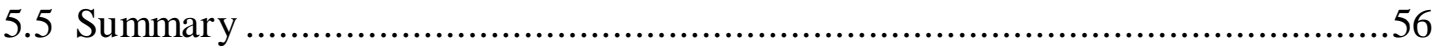

\section{Chapter Six: Conclusion}

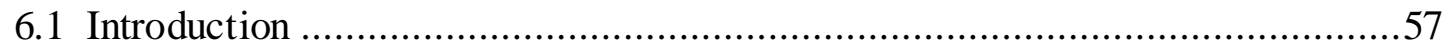

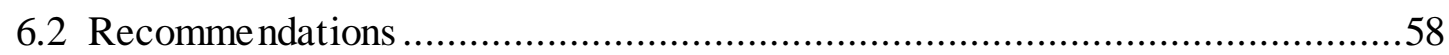

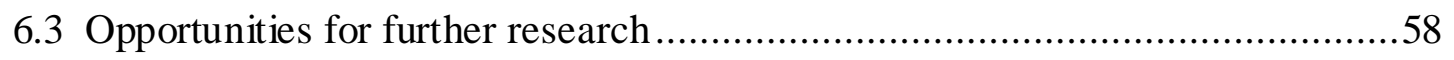

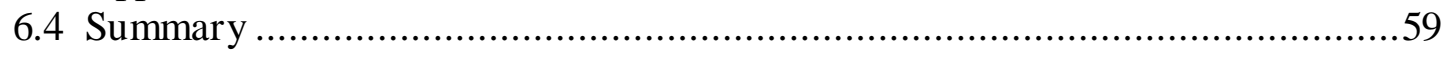

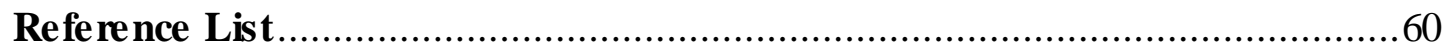




\section{Appendices}

Appendix A: Information and consent form for current mentor teachers ................70

Appendix B: Information and consent form for past mentor teachers ....................73

Appendix C: Information and consent form for third year teachers .......................76

Appendix D: Information and consent form for PRTs......................................79

Appendix E: Information and consent form for school principal .........................83

Appendix F: Survey questions for mentor teachers...................................... 86

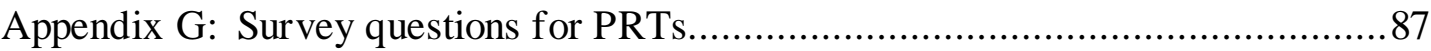

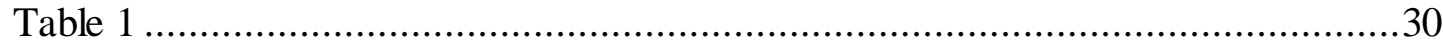

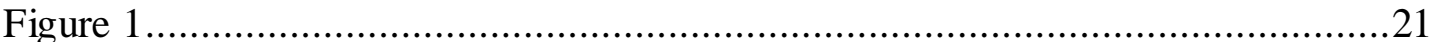

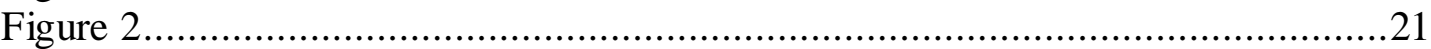

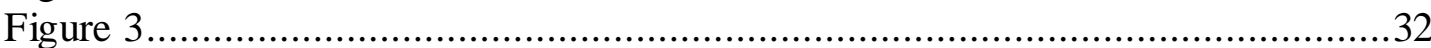

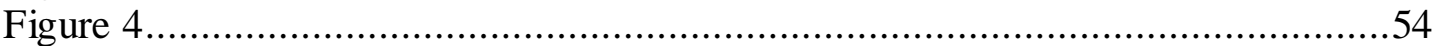




\section{Chapter One: Introduction}

\subsection{Overview}

Research highlights the importance of effective mentoring, both to those directly involved in the process and to the education system as a whole. Mentoring is a very relevant topic in education at the time of writing with the New Zealand Teachers Council (NZTC) introducing guidelines at the end of 2011 for implementation in 2012 to guide the mentoring process and shift it from an advice and guidance programme to a transformative learning process. This study is set in an intermediate school in Wellington, New Zealand with a roll of approximately 500 students. The purpose of this study was to establish how effectively educative mentoring guidelines were being implemented in an intermediate school, identify challenges to this process and identify enablers to an effective educative mentoring process.

\subsection{The New Zealand Context}

Currently, beginning teachers or Provisionally Registered Teachers (PRTs) in New Zealand undertake a two-year induction process after the completion of their teacher education programme. During their first two years as a PRT, they are assigned an experienced teacher as a mentor at their school who meets with them and guides their progression towards achieving the Registered Teacher Criteria (RTC). The RTC are used to assess teachers, before they are recommended for full registration. They describe the professional knowledge, relationships and values that are required and reflect current thinking and practice on teaching (NZTC, 2010). The criteria are set by the NZTC who are the regulatory body for teachers in New Zealand, and whose purpose is to provide leadership for teachers and contribute to high quality teaching (NZTC, 2013a).

All schools are provided with "policy, guidelines, funding and time” (Langdon, 2011, p. 244) to enable their PRTs to meet the RTC. Funding is provided by the Ministry of Education, which allows the PRT to have one day a week out of the classroom in their first year, and half a day a week in their second year. This release time can be used in a number of ways, for example for observations of the PRT's teaching by their mentor, conducting their own observations, or attending professional development courses. PRTs must keep records of how this release time is spent and collect 
documentation as evidence that they meet the criteria set out by the NZTC. The mentor teacher is responsible for signing the documentation that shows their PRT has met the criteria at the end of the two-year period and mentors are paid $\$ 4,000$ per year for this role. Once the two-year induction process is completed and the mentor teacher and principal agree the PRT meets the RTC, the PRT can apply to the NZTC to become a fully registered teacher. The NZTC randomly selects $10 \%$ of the applications, and asks the applicants to provide supporting documentation that shows they have met the RTC. The PRT must send to the NZTC this documentation for them to read and decide whether the criteria have been met and if they should be admitted to the profession as a fully registered teacher (NZTC, 2011b).

In 1989, with the introduction of Tomorrow's Schools (education reforms that shifted the financial and administrative management of schools to individual school boards of trustees (NZCER, 2013)), the responsibility of the induction programme moved from the government to teachers themselves (Howe, 2006). New Zealand's induction programme is often referred to as exemplary (Howe, 2006), mainly because of the release time made available to beginning teachers to assist them with their professional development.

In New Zealand, the formal induction and mentoring process began in 1985 (Langdon, 2011) and focussed on advice and guidance. Despite the surge in popularity of mentoring from the 1980s, recent research within New Zealand indicated that these programmes were inconsistent and focused on fitting in, rather than being transformative with a focus on good teaching (Cameron, Dingle \& Brooking, 2007). There are two main reasons the NZTC developed new guidelines for the mentoring of beginning teachers. One is the shift in thinking around mentoring from being an advice and guidance programme to becoming a transformative process, where not only is the teacher's practice transformed but so is the culture of the school (Gless, 2006). The second reason is that research has indicated inconsistencies in the delivery of induction programmes (Langdon with Flint, Kromer, Ryde, \& Karl, 2011). The guidelines aim to move practice within schools towards a co-constructed professional learning relationship between mentor and PRT (NZTC, 2011a). Currently in New Zealand, mentor teachers are not required to undertake any training to prepare them for the role. None of the mentor teachers involved in this study had taken part in any professional development on the mentoring of beginning teachers. 


\subsection{Educative Mentoring Guidelines}

In 2008, the NZTC conducted research around New Zealand to assess the quality of the mentoring and induction programmes that were occurring in schools. As a result of the findings, the NZTC developed draft Guidelines for Induction and Mentoring and Mentor Teachers to help mentors move towards educative mentoring. These guidelines were trialled in schools around the country over a two-year period. Following this trial, the guidelines were finalised and booklets sent out containing the guidelines into schools at the end of 2011 for implementation in 2012. The guidelines intend to "support mentor teachers to:

- create and implement...a high quality programme of induction and mentoring within their setting

- be clear about what their role entails

- know what professional learning and development is needed for their role

- develop educative approaches in their day-to-day practice” (NZTC, 2011a, p. 4).

The booklets are intended to provide support to programme leaders of mentoring, mentors, PRTs and any teachers who require mentoring as part of their on-going professional development. The booklet summarises characteristics of educative mentoring and gives examples of what educative mentoring looks like in practice, as well as contrasting limited mentoring with high quality educative mentoring. For example a limited mentoring approach may have the mentor teacher doing most of the talking and provides short-term fixes to problems that arise, whereas educative mentoring focuses on long-term results and the mentor helps the PRT build up their teaching practice to solve problems themselves (Langdon, 2011). As these guidelines are have an educative mentoring focus they are referred to as the educative mentoring guidelines in this study.

\subsection{Intermediate school context}

This study is situated within an intermediate school context. An intermediate school in New Zealand is a school that caters for middle level education, specifically Year 7 and 8 students and is often referred to as a 'middle school'. Students at this level are typically aged between 11 and 13. An intermediate school aims to cater for this period of adolesence, addressing the specific needs that are relevant to this age group. 
Dinham and Rowe (2008) define a middle school as "a separate organisational unit ... for young adolescents" (p. 10) explaining "that 'middle schooling' refers to a particular philosophy or set of principles about teaching, learning and curriculum for young adolescents” (p. 10).

A main feature of many intermediate schools in New Zealand is that students stay in one classroom with one teacher for the majority of the school day, but have additional specialist classes throughout the week. These specialist classes include subjects such as music, art, food technology and workshop. In this way intermediate schools provide a transition between primary school and secondary school because students have the continuity of the integrated curriculum delivery model which they had at primary school, while experiencing specialist teaching where they move around the school to go to specialist rooms which happens at secondary school (Dinham \& Rowe, 2008). Another reason that intermediate schools are unique is that all staff teach at the same level. This means teachers are easily able to plan and teach collaboratively and professional development has high relevance across the staff. Beginning teachers within an intermediate school context experience challenges specific to that level and "many veterans of the classroom would contend that instructing young adolescents in a middle school environment is perhaps the greatest challenge of all, especially for a brand new teacher” (Carnegie Council on Adolescent Development, 1990 as cited in Ingwalson \& Thompson, 2007, p. 43).

\subsection{Significance of Study}

The NZTC developed guidelines to support the mentoring of beginning teachers in New Zealand schools; these guidelines were based on the principles of educative mentoring and represented a move away from the advice and guidance programme, which saw the use of the term 'tutor teachers', towards a transformational mentoring process with the term 'mentor teachers'. These guidelines were introduced into schools at the end of 2011, for implementation in 2012, and this study presented an opportunity to examine the implementation of these guidelines and any challenges that were faced with implementation. The guidelines were introduced with no requirements around the training of mentor teachers. The mentor teachers in this study had not undergone any mentoring training, although they were shown the booklets at the start of the year and given an opportunity to discuss them with their PRT. As 2012 was the first year the guidelines were used in schools, there had been 
no published research on the success of their implementation. This study was able to examine the implementation of the guidelines in an intermediate school, and identify challenges and successes associated with mentoring.

\subsection{Researcher Perspective}

I am a classroom teacher, syndicate leader (a teacher who leads a team of teachers) and mentor teacher at NIS (a pseudonym used to protect the school's anonymity) where the study takes place. I have taught at NIS since I completed my teacher training and completed my two-year induction process at the school. I am in my eighth year of teaching and my fourth year as a mentor teacher. While completing my Masters degree, I became interested in coaching and mentoring while completing a paper on the subject at Victoria University of Wellington. Through reading the literature I became aware of the possibilities of mentoring, and saw the introduction of the new mentoring guidelines as an opportunity to examine the challenges of their implementation within a school context. As a syndicate leader and a mentor teacher, I have a real interest in promoting and adding to the learning of beginning teachers. Throughout the period of this research, I was on study leave.

\subsection{Research questions}

In order to explore this topic, the main question that frames the research is:

How effectively are the educative mentoring guidelines being implemented in an intermediate school?

The sub-questions that further guide the research are:

- What are the challenges of mentoring beginning teachers in an intermediate context?

- What needs to happen to enable effective mentoring to occur in an intermediate context?

- How does the tension between assistance and assessment affect the mentoring relationship?

\subsection{Overvie w of the thesis}

This thesis will begin with a literature review that explores mentoring and examines the research behind effective mentoring, looking in detail at educative mentoring. The methodology section will describe the process used to gather data for this study, 
and justify the different methods used. The findings section will set out what was found out from the data collected. The discussion section will answer the research questions and discuss the implication of the findings, linking them to literature. Lastly, the conclusion section will make specific recommendations for mentoring at NIS, and identify areas for further research. 


\section{Chapter Two: Literature Review}

\section{$2.1 \quad$ Introduction}

The primary purpose of this literature review is to gain a clear understanding of current thinking around best practice mentoring for beginning teachers, and to examine the shift in thinking within mentoring since its formal introduction into education in the 1980s. Educative mentoring guidelines developed by the NZTC to guide the mentoring and induction process in New Zealand were introduced at the end of 2011 for implementation in 2012 and as yet there is no published research on their implementation. This study presents a unique opportunity to explore the challenges of implementation of educative mentoring at one intermediate school and offer suggestions for future implementation.

This chapter is divided into eight main sections: section 2 explores mentoring; section 3 looks at changes in mentoring; section 4 focuses in on educative mentoring; section 5 explores components of an effective mentoring programme; section 6 describes the benefits of an effective mentoring programme; and section 7 examines the tension between assistance and assessment; and section 8 looks at exemplary mentoring programmes.

\subsection{Mentoring}

Literature often refers to the mythological roots of the word mentor (Cain, 2009), with it first appearing in the 'Odyssey', the epic Greek novel by Homer, as the name of a character who was entrusted to advise a young boy named Telemachus while his father was away. Since the appearance of this character in the 'Odyssey', the term mentor has been linked with the idea of a more experienced person providing a less experienced person with advice and support (Clutterbuck \& Megginson, 1995). Mentoring occurs across a range of professions, and its purpose is to help new professionals develop the skills needed to be successful in their industry (Hargreaves \& Fullan, 2000). It is useful for guiding a new practitioner in a field into a "community of practice" through modelling (Murphy, Mahoney, Chen, MendozaDiaz and Xiobing, 2005, p. 344). Becoming proficient in any field requires "commitment and some form of mentoring or coaching to achieve predetermined 
goals” (Langdon, 2011, p. 242). Although mentoring is a broad term and there are disagreements around the definition, there is a common thread throughout the literature which says that mentoring is an holistic approach to helping, with the emphasis on someone wise passing on knowledge to someone with less experience (Douglas, 1997; Hobson, Ashby, Malderez \& Tomlinson, 2009; Parsloe \& Wray, 2000; and Roberts, 2000).

\subsection{Mentoring over the years}

The use of mentoring as a strategy to support beginning teachers has steadily increased since the early 1980s (Marable \& Raimondi, 2007; Hobson et al., 2009; Howe, 2006). As educators looked to increase the number of teachers, retain newly qualified teachers and reward experienced teachers (Hobson et al., 2009) mentoring became increasingly popular as a strategy. Interest in mentoring has grown since research has suggested that it has many benefits including teacher retention (Carter \& Francis, 2001, Darling-Hammond, 2003, Howe, 2006, Sweeny, 2008, Langdon et al., 2011, McDonald \& Flint, 2011), job satisfaction (Whisnant, Elliott \& Pynchon 2005), higher quality of teaching and learning (Achinstein \& Athanases, 2006; He, 2009; Howe, 2006), an increase in student achievement (Achinstein \& Athanases, 2006) and benefits to mentor practice (Little, 1990).

When mentoring first formally emerged in education during the 1980s, induction programmes were focused on supporting the PRT rather than challenging their practice (Langdon, 2011). However, over the past twenty years the emphasis has shifted to focus on the holistic development of a whole teaching career rather than a 'just in time' fix for problems as they occur (Wang \& Odell, 2002). This holistic mentoring process goes beyond the narrow relationship between the assigned mentor and mentee and includes other teaching colleagues, friends, senior management and family (Waterman \& Ye, 2011). As views on mentoring have moved from just providing support and advice to transforming practice, the skills required of mentors have expanded dramatically (Whisnant et al., 2005). The view of mentoring as transformative is called ‘educative mentoring' (Gless, 2006).

\section{$2.4 \quad$ Educative mentoring}

Educative mentoring is individualised professional development (Norman \& FeimanNemser, 2005) whose impact "not only depends on appropriate matches, time, and 
training, but also on the expectations that mentors and novices hold for one another and what they actually do together" (Norman \& Feiman-Nemser, 2005, p. 680). Educative mentoring is both responsive and interpretive, and tied closely to a vision of expert teaching (Norman \& Feiman-Nemser, 2005). In practice, this means that a mentor responds to their PRT's present needs, while helping them interpret their students' learning and behaviour, and working together to find a way to move learning forwards (Norman \& Feiman-Nemser, 2005). An educative mentoring approach focuses on the teacher as a learner, who needs to develop a principled teacher practice (Langdon, 2011).

Educative mentoring has two dimensions. The first is that of the mentor teacher providing emotional support for the PRT to allow them to develop and the second is the mentor teacher providing professional support and challenge that is based on understanding teachers and how they learn (Rippon \& Martin, 2006). One of the most important aspects of educative mentoring is that the mentor provides a balance of support and challenge (Norman \& Feiman-Nemser, 2005) and in order for beginning teachers to be successful they need to experience both of these aspects (Maynard, 2000, as cited in Street, 2004). This idea of challenge is in contrast to earlier interpretations of mentoring which was based on a deficit model of fixing problems in the PRT's classroom rather than extending, challenging and engaging in learning conversations with the PRT (Norman \& Feiman-Nemser, 2005). Educative mentoring requires mentors and mentees to learn through dialogue and social interactions (He, 2009) rather than the mentor transmitting their knowledge. This reciprocal learning process is an important aspect of educative mentoring and the learning is co-constructed by both the mentor and mentee. (NZTC, 2011a). Educative mentoring combines both procedural roles and counseling and supporting roles and the most effective mentors are those who can work out when each type of support is needed (Rippon \& Martin, 2006).

\subsection{Components of an effective mentoring programme}

There are a number of conditions that are necessary in order for an effective, educative mentoring programme to exist. When these conditions are present, it is more likely that effective mentoring will occur. The most important components of an effective mentoring programme are: carefully selected mentors, trained mentors, structure, and basing the mentoring programme within a community of support and 
these will be discussed in the following sections.

\subsubsection{Care fully selected mentors}

Sitting at the heart of the mentoring process is the relationship between the mentor and the mentee; it is key to the success of the mentoring partnership (Garvey \& Alred, 2010). The ability of the mentor to quickly build a trusting relationship (Moir, Barlin, Gless \& Miles, 2009) is vital as successful relationships are built on trust (Pitton, 2006). It is not enough to simply assign a beginning teacher to an experienced teacher and expect mentoring to occur, and it is important to note that not all effective teachers are effective mentors (Hobson et al., 2009; McDonald \& Flint, 2011). The success of mentoring programmes can be attributed to how mentors are selected (Hobson et al., 2009; Aitken et al., 2008; Cameron et al., 2007), and "the most important element of any mentoring program is the quality of the mentor" (Moir et al., 2009, p. 23). Mentor selection and the matching of mentor to mentee are the two biggest problems with mentoring programmes (Sweeny, 2008). When those involved in the process are able to choose who they are paired with there is more chance of a successful mentoring relationship (Carter \& Francis, 2001) and many programmes have failed simply because this has not happened (Long, 2009).

\subsubsection{Trained mentors}

Research has established that mentors need to undertake formal training in order for the mentoring process to be a success (Hobson et al., 2009; Howe, 2006; Langdon, 2011; McDonald \& Flint, 2011; NZTC, 2011a; Pitton, 2006), preferably before the start of the school year (Long, McKenzie-Robblee, Schaefer, Steeves, Wnuk, Pinnegar, \& Clandinin, 2012). The first priority of a mentoring programme is to select the most talented mentors, and the second is to train them and build their capacity as mentors (Moir et al., 2009). To be effective, mentors need training that provides ongoing opportunities for thorough, quality professional development and contexts in which to develop their mentoring skills (Feiman-Nemser, 2003), increase their expertise and enable educative mentoring to become a natural part of their practice (McDonald \& Flint, 2011).

Mentoring requires specific skills that need to be taught and cannot just be assumed (NZTC, 2011a) and mentors should not be put into the role with no preparation at all (Barrera, Braley \& Slate, 2010). Without specific training, mentors may only be 
concerned with PRTs fitting in with the culture of the school and will "reproduce the status quo" while not fulfilling their mentoring potential (Britton et al., 2000). Mentoring will not be transformative, as it should be under educative mentoring guidelines. Schools have the potential to be "dynamic and active agents of change" when reciprocal learning occurs within mentoring partnerships (Long et al., 2012) and if mentors are just producing clones of themselves or reproducing the status quo this opportunity is lost. Research conducted by Evertson and Smithey (2000) found that when beginning teachers worked with mentors who had been trained, they became more effective classroom practitioners and were better able to give instructions, maintain student engagement and develop routines than beginning teachers whose mentor teacher had no training. The conclusion drawn from this was that just being assigned a mentor is not enough - the mentor must have relevant skills and knowledge also (Norman \& Neiman-Fenser, 2005).

\subsubsection{Programme structure}

Mentoring is more effective when it is well designed and well supported (DarlingHammond, 2003). Effective mentoring occurs when an experienced teacher guides a beginning teacher to become the best teacher they can be, through a mixture of support and challenge. In order to do this, an effective mentoring programme needs to be structured and supported, with clear guidelines and well-defined goals (PiggottIrvine, Aitken, Ritchie, Ferguson, \& McGrath, 2009; Marable \& Raimondi, 2007; Barrera et al., 2010). This structure and support includes clear expectations, clarity of process, and provision of time for the process to occur. The provision of time was often said to be the most important factor in an effective mentoring relationship (Barrera et al., 2010; Marable \& Raimondi, 2007; Piggott-Irvine et al., 2009; Roehrig, Bohn, Turner, and Pressley, 2007).

\subsubsection{Based in a community of support}

While research shows formal mentoring programmes are important, Piggott-Irvine et al. (2009) found that the biggest indicator of success at schools with effective mentoring programmes was PRTs having access to a culture of support across the school, rather than feeling limited to support from one formal mentor. The most effective beginning teachers seek advice both inside and outside of the mentoring relationship (Roehrig et al., 2007) and it is important to have a school climate that 
encourages this environment of assistance seeking (Barrerra et al., 2010).

The professional learning that goes beyond PRT meetings and is embedded in the whole school culture helps PRTs to gain an understanding around expectations and expert teaching practice (Langdon, 2011). The support for beginning teachers needs to come from all levels across the school and senior management play an important role in supporting the mentors. Some of the ways they need to support mentors include making mentors accountable to the programme leader, helping mentors to grow in their mentoring and recognising the importance of informal mentoring (Sweeny, 2008).

\subsection{The be nefits of an effective mentoring programme}

The effective mentoring of PRTs is crucial to enable them to develop professionally, stay in the profession, and become effective mentors themselves (Langdon et al., 2011)). Mentoring is also important in "attracting better candidates; reduced attrition; improved job satisfaction; enhanced professional development and improved teaching and learning” (Howe, 2006, p.287). The emotional support offered by effective mentors helps to increase the confidence of PRTs. This means PRTs are able to "put difficult experiences into perspective, which increases their morale and job satisfaction” (McDonald \& Flint, 2011, p. 36).

There are a number of benefits to an effective mentoring programme. These benefits extend to the mentor, mentee, school and teaching profession. These benefits include an improvement in teacher quality, improvement in student achievement, reduction in the attrition rate, improvement in the mentor's capabilities and ongoing development of the teaching profession. These are explored in greater detail in the following section.

\subsubsection{Improvement in te acher quality and student achievement}

The greatest factor that impacts on student outcomes is the quality of the teacher, and effective mentoring improves teacher quality (Moir et al., 2009). Research has shown that beginning teachers who receive mentoring perform better in the classroom in many ways, including planning and managing student behaviour (Evertson \& Smithey, 2000). Evidence has been building that indicates students in the classrooms of beginning teachers who have been mentored show higher achievement than those who have not been mentored (Achinstein \&Athanases, 2006; Ingersoll \& Strong, 
2011). Not only do mentoring programmes positively effect classroom practice, but the more thorough and regular the mentoring, the better the teachers and students do (Moir et al., 2009).

The process of learning to become a teacher does not end at graduation from teacher education programmes; rather the first two years of teaching are an extension of the teacher training process (NZTC, 2011b). Indeed, research has indicated that teacher education is not enough to prepare beginning teachers for the classroom and that the learning that occurs during the first two years of teaching is the most important for effective teacher development (Feiman-Nemser, 2003). Beginning teachers who work in isolation face "a slow and painful learning curve" (Moir \& Gless, 2001, p. 110) and the importance of being involved in an effective mentoring programme cannot be overstated for raising teacher effectiveness and student achievement.

\subsubsection{Reduction in attrition of trained teachers}

The rate of attrition of teachers is causing concern in countries around the world due to the economic impact (Waterman \& He, 2011; Carter \& Francis, 2001;) and the negative effect it can have on student outcomes (Whisnant et. al, 2005). In the United States, it is reported that between $30 \%$ and $50 \%$ of teachers leave the profession within the first five years (Carver \& Feiman-Nemser, 2009). In many countries around the world, policy makers believe "that early career teacher attrition is of economic, social, and educational concern” (Long et al., p. 7). With a growing world population, it is ever more challenging to meet the demand for more teachers when so many leave the profession (Sweeny, 2008). Also, some of the best teachers with the most experience are leaving the profession without passing on the benefit of their experience and mentoring encourages the experienced teachers to pass on their knowledge. Teachers involved in the effective mentoring programmes are more likely to stay in the profession (Darling-Hammond, 2003; Moir et al., 2009). However, as Ingersoll and Strong (2011) point out, not all attrition of beginning teachers is negative as the departure from the profession of a low performing teacher early on in their career is beneficial to both the students and the school. Although it is difficult to establish any direct link between mentoring and retention (Waterman \& Ye, 2011) and there is a lack of research establishing a link (Cameron et al., 2007) the belief still holds that mentoring does decrease the rate at which teachers leave the profession. 


\subsubsection{Increase in mentor capabilities}

The benefits of mentoring extend not only to the mentee. Quality mentoring improves the practice of the mentor too (Roehrig et al., 2007). Reasons for this include increased reflection and the desire to be an effective model of excellent teaching (Sweeny, 2008). According to Moir and Bloom (2003), the benefits a mentor may receive from the mentoring process include replenishment and "the skills and passion to make lifelong teacher development central to school culture” (p. 58). Little (1990) indicates that one of the reasons for the rise of mentoring over the last thirty years is the ability of mentoring to "reward and retain the capable teachers" (p. 297).

\subsubsection{Development of the teaching profession}

Research supports the benefits of mentoring to the education system as a whole and the mentor teacher themselves (Shinners \& Sweetland, 2008). Teachers who take on the role of mentor are not only making a valuable contribution to their mentee, but also help develop the professionalisation of teaching (Moir, 2012). The importance of mentoring beginning teachers cannot be overstated and mentoring "offers an opportunity to make or break the new professional, and ultimately the profession" (Achinstein \& Athanases, 2006, p. 4). Mentors as leaders can reshape the teaching profession (Achinstein \& Athanases, 2006) and "comprehensive mentoring can transform schools into vibrant learning communities” (Moir, 2013, New Teacher Center, para. 2). Zey's mutual benefits model (1984) shows benefits to both those directly involved in the process and to the organisation as a whole, in this case the school.

\subsection{Tension between assistance and assessment}

In primary and intermediate schools, it is the mentor teacher who is responsible for assessing their PRT and deciding whether they are ready for full registration, with the principal (or person who leads the mentoring programme) also needing to agree. The form that is filled out by the mentor teacher states: "I have appraised this teacher in accordance with the criteria listed below. I recommend that this teacher is given full registration as a teacher in New Zealand, because their demonstrated performance is satisfactory and s/he meets all the Registered Teacher Criteria” (NZTC, 2013b, p. 3). With the responsibility of assessment falling to the mentor, a power relationship can emerge (Rippon \& Martin, 2006) with the mentor teacher wielding power over the 
PRT as they decide whether or not the teacher has met the requirements for full registration. With the same person in charge of providing assistance and assessment, the PRT may be encouraged to conform to the status quo, rather than experimenting with creative or innovative ideas (Rippon \& Martin, 2006). This also may mean that the PRT is less likely to share the problems they need the most help with, as they want to appear capable in order to meet the requirements for full registration (Britton, Raizen, Paine, \& Huntley, 2000).

Within the literature, there has been general agreement that assistance and assessment should be separate, and that the person who is mentoring a PRT should not be the person who assesses them (Feiman-Nemser \& Parker, 1993; Yusko \& FeimamNemser, 2008). However, those who are in favour of mentoring programmes that separate assessment from assistance do not often mention the fact that teachers are playing this dual role constantly (Feiman-Nemser \& Parker, 1993). Yusko and Feiman-Nemser (2008) write of the underlying paradox of incorporating assessment into mentoring, without putting trust and openness at risk. In a study they conducted, they tried to establish whether assistance and assessment could co-exist together in induction programmes. The results showed that although combining the two roles could make mentoring relationships challenging, it did not stop the mentors forming trusting relationships. They concluded that it was both possible to combine assistance and assessment in a mentoring relationship, and indeed impossible to separate them if new teachers are being taken seriously as learners.

Mentoring can be most educative when mentors engage in assistance and assessment structured by appropriate frameworks and processes, get support from a professional community that upholds professional teaching standards, and receive training and ongoing professional development to carry out their important responsibility (p. 924)

When the assistance is meaningful and the assessment responsible, mentors are able to form trustworthy relationships with PRTs (Yusko \& Feiman-Nemser, 2008).

\subsection{Exemplary mentoring programmes}

The New Teacher Center based in Santa Cruz (SCNTC) in the United States is arguably the best-known programme for the induction of beginning teachers (Howe, 2006). Each year, the SCNTC identifies exemplary teachers and releases them from 
the classroom to allow them to mentor full time. The model they have created of professional development for mentors includes academies, a learning community for mentors, and peer coaching (Whisnant et.al, 2005). The benefits of using external mentors include the ability to use mentors who are familiar with the process and also provide each PRT with a specifically trained, experienced mentor (Piggot-Irvine et al., 2009). Aspects of the SCNTC programme could serve as a guide for future mentoring programmes, as they appear to reflect the principles of educative mentoring.

\section{$2.9 \quad$ Summary}

This literature review has examined the shift in thinking within mentoring since its formal introduction to education in the 1980s, moving from a support and advice programme to a transformative, co-constructed, reciprocal learning relationship. It has described key elements of educative mentoring, and identified key components of an effective mentoring programme. The review has discussed the benefits of an effective mentoring programme, and identified tensions that arise between assistance and assessment within mentoring. These tensions will be discussed in more detail in the Discussion chapter. As 2012 was the first year educative mentoring guidelines were implemented in schools, there is as yet no published literature on their implementation. This study provided the opportunity to conduct research in this area. 


\section{Chapter Three: Methodology}

\subsection{Introduction}

This study is a qualitative case study that explores the challenges of mentoring beginning teachers in an intermediate school context. As this study gathered opinions and examined perspectives, it was underpinned by a constructivist paradigm. Data was collected through online surveys, focus groups and interviews. The methodology used helped to answer the research questions by providing information around the mentoring process and exploring opinions and perspectives.

In this chapter, section 2 examines the research aims and sets out the research questions; section 3 looks at the theory underpinning the study; section 4 focuses on the case study; section 5 looks at the change in methodology; section 6 and 7 describe the participants and limitations of the study; section 8 outlines ethical considerations including the conflict of roles; section 9 examines data collection, looking at surveys, focus groups and interviews; and section 10 focuses on analysis and trustworthiness of the data.

\subsection{Research aims}

The purpose of this study was to examine the implementation of educative mentoring guidelines at an intermediate school, and identify challenges and enablers to the process. The methodology was designed to answer this broad research question:

How effectively are the educative mentoring guidelines being implemented in an intermediate school?

These sub-questions further guided the research:

- What are the challenges of mentoring beginning teachers in an intermediate context?

- What needs to happen to enable effective mentoring to occur?

- How does the tension between assistance and assessment affect the mentoring relationship?

\subsection{Theore tical underpinnings}

There are two main frameworks within education research: positivism and 
constructivism. Positivism is the belief that there is an objective truth independent of opinions and perspectives, waiting to be uncovered by the researcher (Robson, 2002). Constructivism is the belief that there is no independent truth but rather, reality is socially constructed (Robson, 2002). In a constructivist framework, knowledge is intrinsically linked to a person's perception. There are multiple perspectives of meaning and knowledge and participants help to construct the reality with the researcher (Robson, 2002). As this study seeks to examine the opinions and perspectives of teachers, it does not seek to uncover one objective 'truth', but looks to examine the multiple realities that exist. Therefore this study is located within a constructivist framework (Denzin \& Lincoln, 2008; Patton, 2002).

Quantitative data seeks to examine independent truth and uncover an objective reality, with a focus on testing a hypothesis (Johnson \& Christensen, 2012). Qualitative research examines behaviour as it occurs in its natural environment (Johnson \& Christensen, 2012). This study is predominantly qualitative in its approach, but also included elements of the quantitative. This approach is known as mixed method and is an effective way of gathering data, as the researcher is not limited to one type of data collection. This widens the scope of data collection and can allow for the bigger picture to emerge.

The online survey gathered mainly quantitative data in order to make comparisons between the mentor teachers with the answers of the beginning teachers. This quantitative data was important because it informed the direction of the study. The survey also asked one qualitative question that allowed for the emergence of opinion and perspective. The focus groups and interview are qualitative in nature as they explore teachers' own realities.

\subsection{Case study}

This study took the form of a case study set within an interpretive research paradigm. Case study research provides a detailed account and analysis of one or more cases as it occurs in a real life context (Johnson \& Christensen, 2012). In this study, the case is the mentoring process at NIS. The goal with a case study is to understand the single case, with the secondary goal of understanding the more general process based on analysis of this single case (Johnson \& Christensen, 2012). In this study, this means an in-depth and holistic understanding of the mentoring process at NIS (the 
real life context), with further understanding of the general mentoring process from analysis of the single case.

This case study used multiple methods of data collection, which is a key characteristic of case study research (Gillham, 2003). Case studies allow researchers to break the quantitative/qualitative divide and data collection in case studies can include both. The research questions of this study are 'how' and 'why' questions, and case studies are the preferred strategy to use when answering questions like these (Yin, 2009).

Case studies have the ability to provide unique examples of authentic people in authentic contexts which "enables readers to understand ideas more clearly than simply by presenting them with abstract theories or principles" (Cohen, Manion \& Morrison, 2011, p. 253). One of the main weaknesses of a case study is in the inability to generalise from its findings (Punch, 2005). However, case studies can result in rich, holistic and descriptive accounts of the phenomenon, which helps the reader to understand the phenomenon as a whole, resulting in "the discovery of new meaning, extend the reader’s experience, or confirm what is known” (Merriam, 1998, p. 28). Generalisation is not always necessary for valuable learning to occur.

\subsection{Change in methodology}

The methodology of this study changed during the course of the research. When planning this study, I thought that the results of the survey may identify common gaps in the mentor teachers' implementation of strategies outlined in the 'Guidelines for Induction and Mentoring and Mentor Teachers'. The areas with the biggest gaps were to be the subject of two workshops, aimed at improving the mentor teachers' use of the strategies that would ultimately lead to an improvement in mentoring practice at the school. However, once the quantitative data and open-ended question in the survey were analysed, it became apparent that while, on the whole, neither mentor teachers nor PRTs thought the mentoring programme was particularly effective, the problem was not perceived to lie with the mentor teachers' implementation of the strategies. The open-ended question at the end of the survey asked for suggestions around ways to improve the mentoring process, and common themes around procedure and process emerged. It showed that the problem lay in differences of opinions of the vision of the mentoring process and issues of implementation and procedure. 
Ethics approval and consent had already been granted to run focus groups and it was decided that this would be the most effective way of gathering a more holistic picture of the mentoring process. Focus groups drew out more information and ideas around what the current barriers were to a successful mentoring programme at the school. An interview with the principal was also conducted in order to gain insight into the 'vision' and purpose of the mentoring process from a senior management viewpoint and consent to this was given by email. By adapting this research as information emerged, the study was able to focus on improving the mentoring process in a valuable way for the school.

\subsection{Participants}

Purposive sampling was used to choose the participants in this study (Denscombe, 2003). Those involved were teachers at NIS who were currently involved in the mentoring process or who had been involved in the past and all current and past mentor teachers were invited to participate. The online survey was sent to five current mentor teachers and three teachers who had recently been mentors. Three first-year teachers, three second-year teachers and two third-year teachers participated in the online survey. The focus groups mainly contained those who were currently involved in the mentoring process. There were five current mentor teachers involved in the focus group, all of whom had only been involved in the mentoring process for 1-3 years (see Figure 1). There was also a teacher who had previously been a mentor teacher who had six years experience. In the PRT focus group there were three firstyear teachers and two second-year teachers (see Figure 2). All participants invited to take part in the study agreed to be involved and completed the study. 
Figure 1

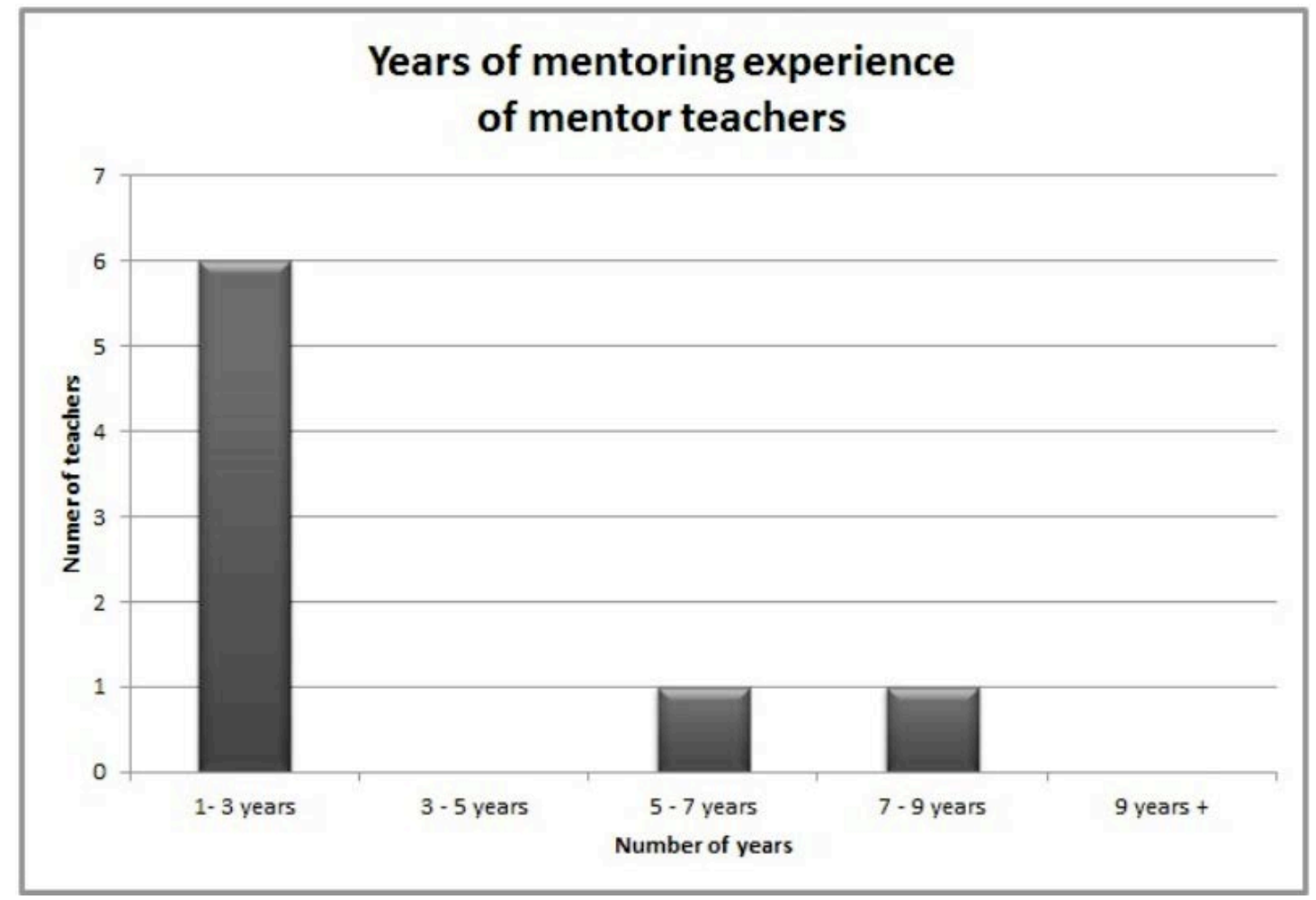

Figure 2

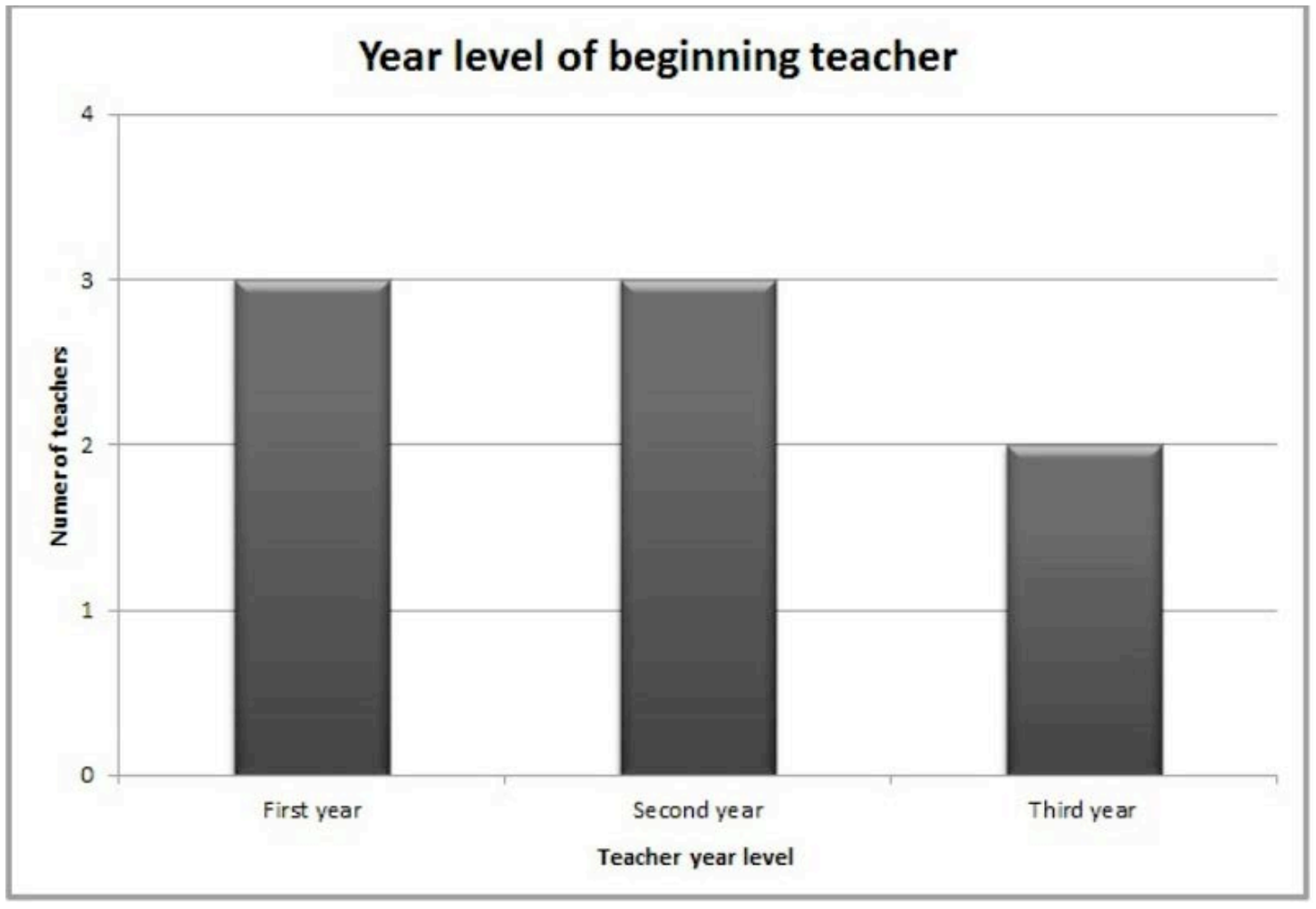

\subsection{Limitations of the study}

One of the main limitations of this case study was that it only involved one school. 
This meant that the findings were specific to one school and may not be the same had the study been conducted in a different school. The findings would have been more comprehensive had the study included other schools. Another limitation is that $75 \%$ of the mentors had only been mentoring for 1-3 years, meaning they had limited experience as mentor teachers.

\subsection{Ethical conside rations}

This study was approved by the Human Ethics Committee, Victoria University of Wellington. It adhered to the New Zealand Association for Research in Education ethical guidelines (NZARE, 2010). Anonymity was not possible in this study as it was conducted face to face at the school I teach at, and participants were told that due to the small scale of the study it was possible that they would be recognised in the thesis, however pseudonyms would be used. When a study does not allow for anonymity, the identity of participants and their responses must be kept confidential and not be shared with anyone other than the researcher (Johnson \& Christensen, 2012). All responses were kept confidential and a pseudonym was used for the school.

Informed consent was gained from all participants and confidentiality of responses was assured (Appendices A-E). Participants are only able to give their informed consent if they are competent, autonomous, involved voluntarily, aware of the right to discontinue, not deceived, not coerced and not induced (O’Leary, 2010). All of the participants in this study were able to give their informed consent. Due to my collegial relationship with the other teachers there was the possibility that teachers felt as though they ought to participate. This was taken into account and the information sheet and consent form were both worded in such a way that it made it easy for potential participants to say no (Appendices A-E.) The consent forms reflect the original direction the study proposed to take, rather than the direction it ended up taking.

\subsubsection{Conflict of roles}

In this study there was the potential for conflict of interest as I was a mentor teacher and a syndicate leader at the school, although off on study leave for the duration of the research. As a teacher at the school it was easy to access staff and prior knowledge of the mentoring process helped inform the rich context needed for the case study. I 
was aware that the relationships I had formed with the staff over the eight years I had taught at the school might affect their responses. As a current mentor to a second year teacher, I did not feel as though I could ask my PRT to participate in the focus group session. I did not want to make her feel uncomfortable answering questions about our mentoring relationship. Her responses to the online survey were used as it was completed anonymously. As I had a personal interest in the findings, I was aware it may be hard to remain impartial and detached (Denscombe, 2003) and I had to keep this in mind when interpreting the data.

\subsection{Data collection}

In this study, three different methods of data collection were used. These were an online survey, focus groups and an interview.

\subsubsection{Survey}

The first stage of data collection was an online survey (Appendices F and G). Its purpose was to gather opinions and perceptions on the mentoring process at school and establish whether educative mentoring guidelines were being followed. Qualtrics (online survey software) was used for this survey. This survey gathered mostly quantitative, ordinal data in the form of a 5-point Likert scale, with participants either agreeing or disagreeing with statements about the mentoring process. At the end of the survey there were two questions that required a written response, designed to draw out opinions and gather suggestions for ways to improve the mentoring process. Open responses have the potential to provide data that is honest and rich (O'Leary, 2010) and in this case it informed the further direction of the study. One of the questions was focused on technology in mentoring relationships, but it was decided to omit this from the study, as it seemed to be outside the scope of the research. Teachers were asked to put in a code unique to them to track how individual responses changed over the period of the study. However, due to the change in methodology only one survey was conducted.

The survey was developed using the educative mentoring guidelines and aimed to establish where there were weak areas in mentoring practice. Mentor teachers had to rank how much they agreed or disagreed with statements on their mentoring practice and PRTs had to indicate if they agreed or disagreed with the statements on their mentoring teachers. The same questions were asked of both mentor teachers and 
PRTs to compare and check for consistency. The statements were adapted from the strategies for mentor teachers as outlined in the educative mentoring guidelines.

\subsubsection{Focus Groups}

Focus groups were used in this study to allow participants to share and discuss their perceptions and experiences of the mentoring process at NIS. A focus group is a group interview where someone leads the discussion with a small number of people (Johnson \& Christensen, 2012). It is more of a discussion, than a formal interview (O’Leary, 2010) and has the advantage of drawing out opinions that might not surface during a more structured question and answer process. The purpose of the focus group was to obtain further information about the mentoring process, finding out people's opinions and improvements for the mentoring process. Benefits of focus groups are that they can provide rich information in a short space of time and produce results that are easily understandable (Johnson \& Christensen, 2012).

Focus groups have the added benefit of those in the group being able hear other people's perspectives, which can encourage them to share their own perspectives. Focus groups provide the researcher with in-depth and rich qualitative data and allow the participants to follow tangents that naturally occur during discussions (O'Leary, 2010). In focus groups there is less need for the facilitator to remain neutral (Denscombe, 2003) and this fitted in with my role as a mentor teacher at the school and my vested interest in the study.

However, negative aspects of conducting focus groups include the fact the participants are not anonymous and it can be difficult for the researcher not to lead the participants in a certain direction. Adding to the problem of anonymity is that the participants may want to be liked or make a good impression (O’Leary, 2010) that can lead them to portray themselves and their opinions dishonestly. In the mentor teacher focus group, these negative aspects did not appear to be a problem, possibly due to the relationship between the mentor teachers, including myself as a mentor teacher at the school. The fact I am part of the group of mentor teachers and could share my experiences and issues may have helped.

\section{Focus group with mentor teachers}

The positive relationship between the mentor teachers seemed to encourage honesty rather than causing them to portray themselves in a false way. The focus group 
provided the opportunity to really speak about what was actually happening and the problems they were facing. The mentor teachers discussed that they wished they had all met together earlier as it was useful to find out what others were doing and interesting to find out that they were experiencing similar problems. In the PRT focus group, it was harder to work out which negative aspects were factors in the responses as I was outside of that group, and am a mentor teacher and syndicate leader.

The focus group session with the mentor teachers was conducted during the staff's professional learning time on a Wednesday morning. School starts half an hour later each Wednesday to allow for morning professional development from 8am until 9am. The mentor teachers met me in one of the classrooms and I explained that the purpose of the session was to gather further information around their perceptions of the mentoring process at NIS. All current mentor teachers attended, plus one teacher who had previously been a mentor and who wanted to mentor in the future. The session lasted approximately 45 minutes. The session was guided by set questions but also followed the natural flow of the conversation. The questions asked were:

- What works well in the current mentoring process?

- What doesn't work well in the current mentoring process?

- In an ideal world, what would a successful mentor teacher/PRT relationship look like?

- What are some of the barriers to success at the moment?

- How would we know we had an effective mentoring programme in place at our school?

\section{Focus group with PRTs}

The focus group session with the PRTs was conducted during the lunch hour. It was not possible to use another Wednesday morning and I was aware of staff being very busy so chose a lunchtime rather than after school. All PRTs attended except for the teacher that I mentor, as previously explained, as I thought it would put her in an awkward position. The session was run in a similar way to the mentor teacher focus group, with set questions guiding the conversation but also allowing the natural flow of conversation to take place. 
The questions asked during this focus group session were:

- What works well and what doesn't work well for you with the mentoring process?

- What has been effective for you as a PRT at this school?

- What would you most like to change?

- In an ideal world, what would a successful mentor teacher/PRT relationship look like?

- What are some of the barriers to success at the moment?

- How would we know we had an effective mentoring programme in place at our school?

Both focus groups were audio recorded using an iphone, which made the recording unobtrusive and allowed me to focus on the conversation at hand without having to take notes. These notes were transcribed to allow for ongoing analysis of the conversations, and were emailed to participants for member checking. Although a down side of only using an audio recording is that all non-verbal cues are not noted (Denscombe, 2003), the use of member checking allowed for participants to give feedback on their comments to ensure their point of view was noted correctly.

\subsubsection{Interview}

The purpose of an interview is to draw out the interviewee's voice and gain their opinion and perspective, with the job of the interviewer to facilitate someone else's ability to answer questions (O’Leary, 2010). The interview was with the principal of the school and it was semi-structured using guiding questions, and followed the natural flow of the conversation. The purpose of this interview was to gain the principal's perspective of mentoring. This interview had a distinct disadvantage. As an employee of the school, I wanted to preserve our relationship and therefore did not feel comfortable asking her certain questions. This limited the scope of data collected from the interview. The interview was audio recorded on an iphone, transcribed and emailed to the principal for member checking. 


\subsection{Analysis of the data}

This section looks at how the data was analysed and explains the process used for both the qualitative and quantitative data.

\subsubsection{Qualitative analysis}

The first qualitative data analysed was that collected in the online survey. The question in the survey asked for suggestions on how to improve the mentoring process at the school. The suggestions were all read numerous times and then common themes were identified. Thematic analysis should be the foundation for the analysis of qualitative data and can provide rich, complex and detailed account of the data (Braun \& Clarke, 2006). Braun and Clarke (2006) describe thematic analysis as "a method for identifying, analysing and reporting patterns (themes) within data. It minimally organizes and describes your data set in (rich) detail” (p. 79). A theme "captures" something about the data and represents a pattern. These themes were used as headings, and under each of these general headings a tick was placed to indicate how many of the participants put forward the same point. The objective here was to identify which suggestions were the most common.

For the interview and the focus group, a similar process was followed. After transcribing the data, I read it through numerous times and identified the common themes that were emerging.

\subsubsection{Quantitative analysis}

The quantitative data came from the online survey that was completed. The quantitative data was used to support the qualitative data, rather than analysed on its own as the study had a small sample size. The quantitative data gathered from the survey was used to inform the direction of the study.

\subsection{Trustworthiness of the data}

When the audio recording of the focus groups and the interview were transcribed, the participants were emailed with the transcription to check I had represented their opinions correctly. Member checking is one of the most important strategies for promoting qualitative research validity (Johnson \& Christensen, 2012). Methods triangulation was used by using more than one method of data collected (Johnson \& Christensen, 2012). 


\subsection{Summary}

This chapter has outlined and explained the research process used. The study was underpinned by a constructivist paradigm and used a mixed methods design. It was a case study of the mentoring process at an intermediate school. The data collection included an online survey that had a mixture of quantitative and qualitative questions and was used to further inform the direction of the study. Further data was gathered in the form of focus groups and an interview and this data built on and added to what was found out in the survey. Thematic analysis was used to interpret the qualitative data collected. 


\section{Chapter Four: Findings}

\subsection{Introduction}

This chapter will present the overall findings from the survey, focus groups and interview. The online surveys gave initial information about the state of mentoring in relation to the educative mentoring guidelines. The focus groups built on the information gained in the survey and provided more specific information, and the interview gathered the principal's perspective of mentoring at NIS. These different data sources will be described in detail throughout this chapter.

\subsection{Findings from the Survey}

The survey (Appendices F and G) was the first stage of data collection, and the findings informed the further direction of the study. It collected both quantitative data in the form of rankings on a 5-point Likert scale, and qualitative data from an openended question, which invited the participants to make suggestions on improvements to the mentoring process.

\subsubsection{Findings from survey: quantitative data}

Table 1 presents the findings from the quantitative data collected from the online survey. It is worth noting that there were eight participants in each of the PRT and mentor groups. This means that $12-13 \%$ represents one person, $25 \%$ two people, $50 \%$ four people etc. The figures have been rounded to equal $100 \%$ for each survey question. Overall, the survey produced findings indicating that overall the mentor teachers and PRTs believed mentors were effectively using the strategies of educative mentoring. 
Table 1: Findings from the survey

\begin{tabular}{|c|c|c|c|c|c|c|}
\hline \multicolumn{2}{|l|}{ Survey statements } & \multirow{2}{*}{$\begin{array}{l}\text { Strongly } \\
\text { disagree }\end{array}$} & \multirow[t]{2}{*}{ Disagree } & \multirow[t]{2}{*}{ Neutral } & \multirow{2}{*}{$\begin{array}{l}\text { Agree } \\
75 \%\end{array}$} & \multirow{2}{*}{$\begin{array}{l}\text { Strongly } \\
\text { agree }\end{array}$} \\
\hline The PRT sets their own & PRTs & & & & & \\
\hline & Mentors & & & $25 \%$ & $63 \%$ & $12 \%$ \\
\hline \multirow{2}{*}{$\begin{array}{l}\text { Goals are co-constructed } \\
\text { with the mentor teacher }\end{array}$} & PRTs & & & $13 \%$ & $75 \%$ & $12 \%$ \\
\hline & Mentors & & & & $12 \%$ & $88 \%$ \\
\hline \multirow{2}{*}{$\begin{array}{l}\text { Meeting and observation } \\
\text { times are planned for } \\
\text { and kept to }\end{array}$} & PRTs & & $12 \%$ & $38 \%$ & $25 \%$ & $25 \%$ \\
\hline & Mentors & & $25 \%$ & $25 \%$ & $50 \%$ & \\
\hline \multirow{2}{*}{$\begin{array}{l}\text { During meetings, the } \\
\text { mentor spends more } \\
\text { time listening than } \\
\text { talking }\end{array}$} & PRTs & & & $13 \%$ & $74 \%$ & $13 \%$ \\
\hline & Mentors & & & $38 \%$ & $50 \%$ & $12 \%$ \\
\hline \multirow{2}{*}{$\begin{array}{l}\text { The mentor teacher uses } \\
\text { effective questioning to } \\
\text { promote deeper thinking } \\
\text { and challenge the PRT's } \\
\text { pedagogical beliefs }\end{array}$} & PRTs & $13 \%$ & & $12 \%$ & $50 \%$ & $25 \%$ \\
\hline & Mentors & & & $37 \%$ & $63 \%$ & \\
\hline \multirow{2}{*}{$\begin{array}{l}\text { The mentor teachers } \\
\text { uses active listening } \\
\text { when the PRT speaks }\end{array}$} & PRTs & & & & $75 \%$ & $25 \%$ \\
\hline & Mentors & & & $12 \%$ & $88 \%$ & \\
\hline \multirow{2}{*}{$\begin{array}{l}\text { The mentor teacher uses } \\
\text { evidence to back up } \\
\text { observation feedback }\end{array}$} & PRTs & $12 \%$ & & $38 \%$ & $25 \%$ & $25 \%$ \\
\hline & Mentors & & $25 \%$ & $12 \%$ & $63 \%$ & \\
\hline \multirow{2}{*}{$\begin{array}{l}\text { The mentor teacher } \\
\text { encourages the PRT to } \\
\text { make their own } \\
\text { decisions }\end{array}$} & PRTs & & & $12 \%$ & $50 \%$ & $38 \%$ \\
\hline & Mentors & & & $25 \%$ & $38 \%$ & $38 \%$ \\
\hline \multirow{2}{*}{$\begin{array}{l}\text { The mentor teacher has } \\
\text { an 'open door' policy } \\
\text { and the PRT can and } \\
\text { does approach them } \\
\text { outside of meeting times }\end{array}$} & PRTs & $12 \%$ & & & $25 \%$ & $63 \%$ \\
\hline & Mentors & & & & $63 \%$ & $37 \%$ \\
\hline \multirow{2}{*}{$\begin{array}{l}\text { The mentor teacher } \\
\text { values the knowledge } \\
\text { the PRT already has }\end{array}$} & PRTs & & & & $50 \%$ & $50 \%$ \\
\hline & Mentors & & & & $37 \%$ & $63 \%$ \\
\hline
\end{tabular}




\begin{tabular}{|l|l|l|l|l|l|l|}
\hline \multicolumn{2}{|l|}{ Survey statements } & $\begin{array}{l}\text { Strongly } \\
\text { disagree }\end{array}$ & Disagree & Neutral & Agree & $\begin{array}{l}\text { Strongly } \\
\text { agree }\end{array}$ \\
\hline $\begin{array}{l}\text { The PRT believes the } \\
\text { mentor is effective }\end{array}$ & PRTs & $12 \%$ & & & $38 \%$ & $50 \%$ \\
\cline { 2 - 7 } & Mentors & & & $50 \%$ & $50 \%$ & \\
\hline $\begin{array}{l}\text { The PRT programme is } \\
\text { highly effective }\end{array}$ & PRTs & & $12 \%$ & $38 \%$ & $38 \%$ & $12 \%$ \\
\cline { 2 - 7 } & Mentors & & $13 \%$ & $64 \%$ & $13 \%$ & \\
\hline
\end{tabular}

In general, the mentor teachers and PRTs recorded answers at similar ends of the spectrum, however, PRTs tended to rate their mentor teachers more highly than mentor teachers rated themselves. Specifically, the PRT group rated the mentor teachers higher than they rated themselves in active listening, keeping to meeting times, using effective questioning, encouraging decision making, having an 'open door' policy and being an effective mentor. There was one PRT who strongly disagreed with four of the statements. These were: using effective questioning; using evidence to back up observations; having an open door policy and being an effective mentor. During the focus group session it emerged that there was one PRT who was paired with a mentor she was unhappy with, and this result may be a reflection of this relationship.

One PRT strongly agreed and three PRTs agreed that the mentoring programme at NIS was highly effective. Three PRTs were neutral about whether or not it was effective, and one disagreed. Half the mentor teachers were neutral about whether or not they were effective mentors and the other half agreed that they were effective mentors. Half the PRT group strongly agreed that they had an effective mentor; three agreed their mentor was effective and only one PRT did not agree that their mentor was effective.

These different perceptions may be a result of differing interpretations of the educative mentoring guidelines by the PRTs and mentor teachers, as well as differing expectations of the mentor process. They may also be a result of the relationship that the PRTs and mentor teachers have, where PRTs rate their mentors as being more effective because of the friendship that exists between them. These possibilities will be discussed in more detail in the next chapter. 


\subsubsection{Findings from survey: qualitative data}

In addition to the quantitative data, there was one question that asked for suggestions on how to improve the induction and mentoring programme at NIS. The common themes that emerged were: the need for clarity and procedures; the need for selection criteria for mentors; professional development for mentor teachers; and ongoing monitoring of the process.

Figure 3 shows the suggestions categorised into three different headings. These headings were: better selection of mentor teachers; clearer procedures and expectations including monitoring of the process; and ongoing professional development and meetings between mentor teachers. PRTs focused on better selection of mentor teachers, and suggested better monitoring of the process. Mentor teachers focused on clearer expectations and procedures as well as training, including meetings with other mentors to exchange ideas and discuss progress. These findings were further explored in the focus groups.

Figure 3: Findings from online survey question:

How might the induction and mentoring programme be improved at TIS?

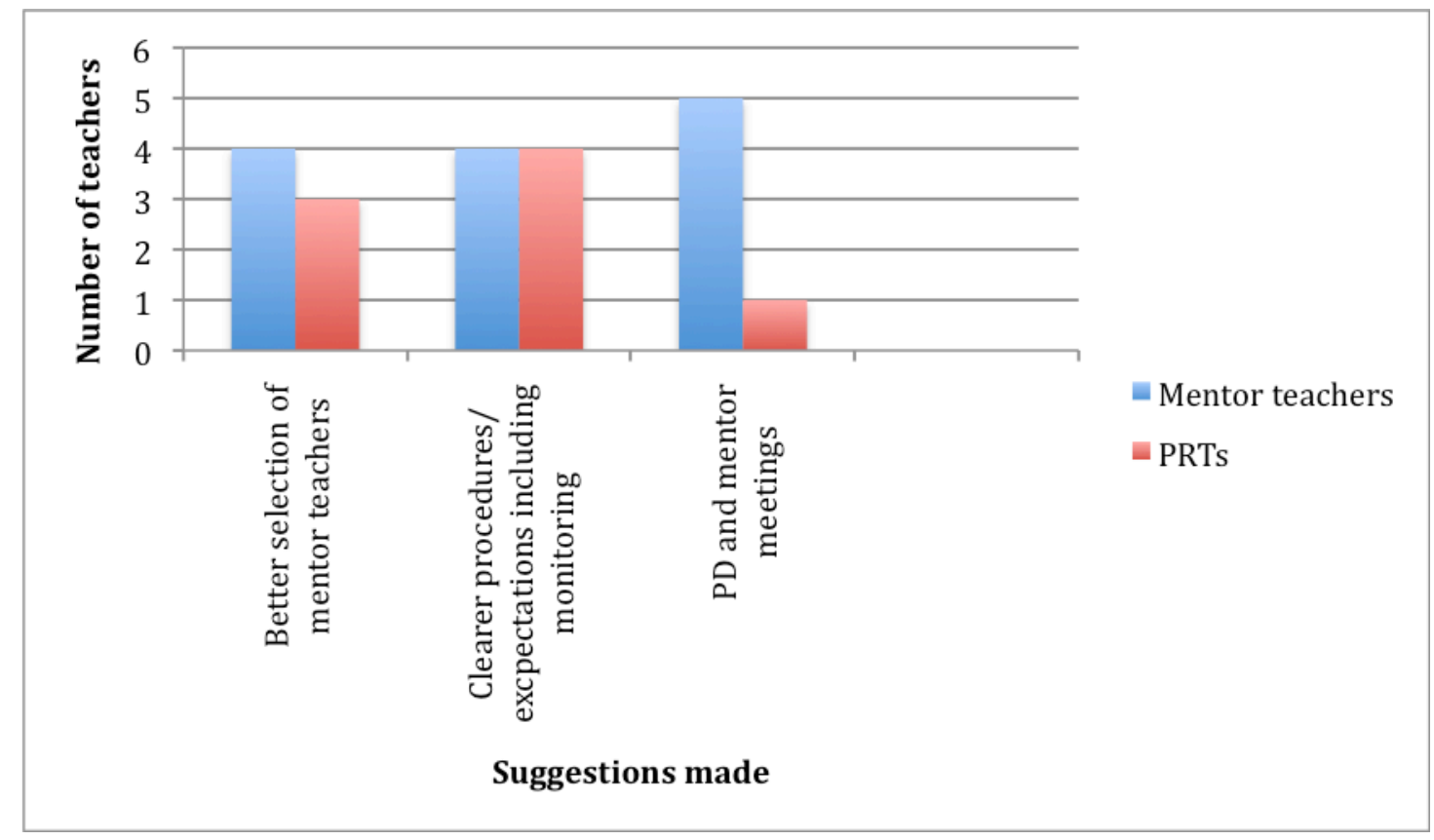

PRTs focused on the need for a better selection process for mentors, as some were perceived as being less effective than others. They suggested better monitoring of the process while mentor teachers focused on the need for clearer expectations and procedures as well as training for the mentor teachers. This included meetings with 
other mentors to discuss issues and progress. These findings were further explored in the focus groups. Overall, these findings were consistent with the literature and highlighted the importance of mentor selection, clear procedures and expectations, ongoing monitoring and professional development. These will be discussed in more detail in the next chapter.

\subsection{Findings from the mentor teacher's focus group}

Five current mentor teachers and one past mentor teacher were involved in this focus group session. The session used questions to guide its direction, however the natural flow of the discussion was followed

\subsubsection{Positive relationships between mentors and PRTs}

All mentor teachers stated that the relationship they had with their PRT was the most positive part of the mentoring process for them. They all commented on the strength of their relationship, one teacher explained:

What's good [in our mentoring partnership] is the relationship; we have conversations every day pretty much.

Another teacher mentioned the ongoing dialogue that happens within their relationship, saying that it continues outside of school as well as within designated meeting times.

\subsubsection{Challenges to an effective mentoring programme}

Throughout the duration of the focus group session, a number of challenges became apparent. These included:

\section{Selection of mentor teachers}

The biggest barrier to an effective mentoring programme for the mentor teachers was the lack of choice around becoming a mentor teacher. Three of the mentor teachers said they did not wish to take on the role and would not do it again the following year. A decision had been made at the school that syndicate leaders would not be mentor teachers, in order to expand the community of support so that the PRT had more people to go to for help. This, however, meant that the number of people who were eligible to be mentor teachers decreased. All syndicate leaders are experienced teachers and many have experience in mentoring. Removing their ability to mentor beginning teachers meant that the mentors had to be found elsewhere and were not 
necessarily best suited to the role of mentor.

\section{Syndicate leader as mentor teacher}

The second point that was raised was the difficulty of being in a different syndicate to your PRT. One teacher mentioned that in such a busy school environment, when something has to be dropped, it is often the PRT meeting time. When you work in the same syndicate as your PRT you can make this time up easily as you see each other regularly. However, when your PRT is in a separate syndicate it is not always so easy to meet up. The teacher who mentioned this was a mentor to two PRTs, one in her syndicate and one in a different syndicate. She said:

This year there's so much pressure, and when something's got to give, the easiest thing to give is the PRT meeting. You can catch up when your PRT is in your syndicate but it's harder when they're not.

Another problem with syndicate leaders not formally taking on the role of mentor teacher is that they often become a pseudo-mentor teacher due to proximity and time spent together. PRTs often direct their questions to their syndicate leader. It became clear there is confusion around the roles of syndicate leader and mentor teacher and what each of these entail. One mentor teacher explained:

You can't put a mentor's role into boxes - eg saying this is the syndicate leader's role, this is the mentor teacher's role. Mentoring is meant to be holistic.

Another mentor teacher said:

The thing I found tricky is the principal has a really good idea in her head what the syndicate leader job is and what tutor teacher job is. It's all well and good her having the picture in her head but I don't have the same picture in my head.

\section{Communication of the purpose, expectations and procedures}

Another barrier is not having a shared vision or purpose for the mentoring programme. The six mentor teachers, PRTs and the principal all had differing ideas on the purpose of the programme. One mentor teacher stated that the principal had a clear idea of what is involved in the mentoring process but it had not been conveyed 
to the mentor teachers. Similarly, there was discussion around the lack of communication of expectations and procedures. Five out of the six mentor teachers did not know what was expected of them and so felt as though they were ineffective. They were unsure of the process for mentoring at NIS.

\section{Tutor teacher versus mentor teacher and the need for professional development}

The use of the term 'tutor teacher' rather than 'mentor teacher' came through in both focus groups and the interview and this will be discussed further in the next chapter. Most mentor teachers felt that their PRT meetings are mainly about meeting the criteria for registration. One mentor teacher said:

At our meetings we're all about 'What do you need to do to make sure you've ticked this box?' The priority is to get the registration. Mentoring exists as an extra. Ten percent of what I do is mentoring, the rest is ticking boxes.

Another said:

I still feel like a tutor teacher, not a mentor.

They spoke of the need for professional development to enable them to develop their skills as a mentor, and move them away from just being a tutor teacher. One mentor teacher said:

Just by being asked to be a mentor and being shown a googledoc and myportfolio page, and given educative mentoring guidelines and being an experienced teacher, doesn't mean you've got the skills or qualities to be a mentor.

All teachers expressed the wish to take part in mentoring professional development, and none voiced concern about using their own time to do this.

\section{Lack of programme leader}

The fact that no one person leads the mentoring programme at NIS was seen as a barrier to its effectiveness. The mentor teachers were not sure who to go to if they had any problems and felt like the programme was not overseen by anyone. One mentor teacher said:

No one has asked how it's going. There is just the assumption that you've 
been at school long enough and you've been teaching long enough so it will be fine.

If there was a clear leader it appeared that it would be easier to know who to talk to and it would make the programme feel like more of a priority to the school.

\subsubsection{Enablers to an effective mentoring programme}

For an effective mentoring programme to exist, the mentor teachers put forward the following suggestions:

- Use a process to select mentors, asking PRTs who they would like to be their mentor (where possible)

- Manage and monitor the programme, revisiting the mentoring relationships to see if they are working

- Have one person in charge of the programme

- Have a process in place whereby the PRTs are empowered to say what is and is not working

- Have an induction day at the start of the year where expectations are outlined and procedures explained.

When asked how they would know if the mentoring programme was effective, one teacher said:

We'd just feel it, because we wouldn't feel like we weren't earning our money or doing the best by our PRT.

The others agreed that the whole process would be clear, from selection of mentors through to PRTs giving feedback on mentor teachers in order to get the best quality of mentors. Generally, the focus group session was an opportunity for the mentor teachers to discuss their issues. They felt there were benefits in having the opportunity to discuss what was going on in their mentoring relationships and how they felt about themselves as mentors. One mentor teacher said:

I'm just glad I'm not in this on my own. Just listening to everybody helps. If we'd hooked up earlier it would have been better but it's taken till September to work this out.

\subsection{Findings from the PRT Focus Group}

This focus group was run during the lunch hour in the meeting room at NIS. There 
were two first-year teachers and three second-year teachers at the session. One of the second year teachers trained and taught overseas and it was her first year of teaching in New Zealand. It is worth noting that unlike the mentor teacher group, the PRTs met regularly to discuss issues and ideas. They saw a need to meet regularly, and arranged and ran these meetings themselves. This focus group session provided the opportunity to hear different perspectives on the mentoring process.

\subsubsection{Positive relationships}

All PRTs spoke of the positive relationships they had with their mentor teacher and all agreed they could approach their mentor teacher at any stage for support. One PRT said:

If you need anything you can go to them and talk to them, having that constant dialogue.

Even in the mentoring relationship that was identified as being ineffective, the relationship was still viewed positively by both teachers involved. The ineffective mentoring relationship appeared to be due to the PRT having a differing view of the purpose of mentoring to the principal's view, and indeed that of the educative mentoring guidelines. The PRT felt as though she needed assistance with the New Zealand curriculum as she had trained overseas, and her mentor teacher was a subject specialist and so was unable to assist her with specific curriculum needs. Both involved enjoyed the relationship but agreed that it was ineffective in terms of mentoring. They also discussed the difficulties in speaking up if something was wrong, and mentioned that it would help if there was a review at the end of each term to establish how things were going with the relationship.

\subsubsection{Usefulness of an e-portfolio}

PRTs are required to keep record of their progress as they move towards full registration, and NIS uses e-portfolios as the medium for aggregating data. Observation feedback, reflections, links to planning and any other documents that are necessary as evidence are all kept on their e-portfolio page. The principal and their mentor teacher have access to this page and can add comments and documents, or just read their reflections. The PRTs found this system useful, with one saying:

Myportfolio works really well for collecting all the information for teacher registration. 
The e-portfolio page also contains links to the NZTC website and other documents that are relevant to mentor teachers and PRTs. This e-portfolio page is useful to the mentoring process as it provides an opportunity for collaboration with other teachers, and a central storage area for documents and video evidence.

\subsubsection{A focus on assessment}

One of the main findings from the PRT focus group was that most of them want the process to focus on assessment and getting them through the teacher registration process. Five out of six of the PRTs believed that the main job of the mentor teacher to get them through the registration. One PRT explained:

Syndicate meetings are about pedagogy. PRT meetings are focused on registration.

Another said:

Tutor teacher and mentor are two different things for me. My tutor teacher is there to get me through registration, nothing else.

With another adding to this by saying:

Especially if we don't get to choose our mentor teacher.

It is worth noting the language used by the PRTs, with all of them referring to their tutor teacher, as opposed to mentor teacher. This will be discussed in more detail in the next chapter.

One PRT mentioned that she wanted more than just assessment, saying:

I don't want my registration process to just be about ticking boxes, I want it to be more about engaging with the concepts behind the criteria.

However, this view did not appear to be shared by the other PRTs.

\subsubsection{Mentor selection and clarity of process}

The PRTs commented on the lack of consistency between the quality of mentor teachers, with one pointing out that there was some jealousy between the PRTS because there were some very good mentor teachers and some who were not as good. One PRT spoke of the "huge differences" between the mentor teachers. Two of the PRTs spoke about how important they believed recent experience in the process of teacher registration is to the role of mentor teacher, suggesting they become mentor 
teachers next year as third year teachers.

They also commented on the process, with one saying:

There doesn't seem to be any school wide direction of how to do it. Should there be some kind of continuity?

Another mentioned:

My mentor teacher doesn't know where the finish line was, so she can't direct me towards it.

There are similarities between the views of the mentors and the PRTs in terms of what is currently working well. The main similarity is that they all view the relationship they have as positive, including the one partnership where mentoring is not seen as being effective. The differences are in how effectively the PRTs feel the mentor teachers are implementing the guidelines and providing mentoring, and this will be discussed in more detail in the next chapter.

\subsection{Findings from the interview with the principal}

This interview was conducted in order to get the principal's perspective on mentoring and to gain a clear picture of the school's overarching mentoring vision and purpose, establishing whether this vision was shared with those involved in the mentoring process. As the interview was the last method of data collection to be conducted, earlier focus group sessions had indicated that the mentor teachers did not seem to be aware of the vision of senior management.

The principal's view of mentoring was that a mentoring relationship should be focused on support and challenge. She acknowledged the need for the relationship to be deep enough to enable the challenge aspect to occur, and recognised the importance of establishing positive, mentoring relationships.

For me it [mentoring] would be around that support and challenge. So it's a relationship that is strong enough or deep enough so the mentor teacher is able to support but also to challenge.

She saw mentoring as becoming a more collegial process rather than the experienced teacher just passing on wisdom and knowledge. She viewed it as a two-way relationship where both mentor and PRT learn, and sees the role of mentor teacher as a real leadership opportunity. 
Probably the ultimate would be where it then becomes a two-way thing where it becomes more collegial than more experienced teacher and open learner.

The principal stated that if there was an effective mentoring programme in place it would be apparent to those involved. Mentor teachers would have a clear understanding of what they were supposed to be doing, and would know whether or not they were doing it correctly. Mentor teachers would also feel fulfilled by the role and PRTs would feel supported and their knowledge and skills would be increasing.

You'd know because your beginning teachers or mentor teachers would feel supported and be growing in their professional practice. Your tutor teachers would be getting fulfillment from the role they are doing and probably tutor teachers would have a good understanding of what it is they are supposed to be doing so they know if they're doing it right or not.

The principal highlighted the tension between experienced teachers or newer teachers being mentors, and appeared to have mixed feelings about which was best, stating:

I favour younger teachers to do the role of tutor teacher because they are closer to the action and they've just done it, but then they don't have the wisdom of a more experienced teacher.

The discussion moved to talking about someone being in charge of the programme and she agreed that this would be a good idea. She also spoke about the one mentor teacher who had two PRTs saying:

I find it fascinating the role that [one of the mentor teachers] has been playing. We are hugely restricted by the rules that say you can only be paid once.

When discussing mentor selection the principal said:

One of the problems you run into is that you run out of staff to be tutor teachers.

Interestingly, the principal also used the term tutor teacher, rather than mentor teacher. Her view of mentoring was different to both the PRTs and mentor teachers, in that she viewed mentoring as a leadership opportunity for the mentors. She was also the least assessment focused and appeared to have an educative view of 
mentoring. She had a similar view to the mentor teachers on how those involved would know when mentoring was effective, and agreed with mentors and PRTs on the importance of a strong relationship.

\subsection{Summary}

This chapter has set out the findings from the survey, focus groups and interviews. The findings have shown a number of ways those involved in the process believe it could be improved and identified common barriers to success currently. There are definite similarities between the views of those involved on what the current barriers to success are, and ways that these can be addressed are discussed in more detail in the following chapter. 


\section{Chapter Five: Discussion}

\subsection{Introduction}

This case study was designed to find out how effectively educative mentoring guidelines were being implemented in an intermediate school, and to identify barriers and make recommendations to enable the mentoring process at NIS to improve. Originally, the study intended to identify gaps in mentoring practice and provide professional development for mentor teachers to assist the implementation of the new educative mentoring guidelines. Although the survey results indicated that PRTs and mentor teachers both perceived that mentors were already implementing the guidelines, teachers involved in mentoring did not think the process was highly effective. Suggestions made in the survey for improvements to the process indicated that those involved believed the problems stemmed from a lack of clarity around procedures, process and expectations. This led to focus groups to uncover more about these issues and gather recommendations for improving the mentoring process at NIS. The data also uncovered an underlying barrier to the whole mentor process. This was the differing perception of the purpose of the mentor programme. This lack of a shared purpose appears to be the cause of most of the other challenges identified by this study.

The main research question that this study attempted to answer was: how effectively are the educative mentoring guidelines being implemented in an intermediate school? In order to answer this question, sub-questions guided the research. These subquestions covered the challenges and enablers to mentoring beginning teachers, and examined the tension between assessment and assistance, which became apparent while conducting the research. The findings of this study are discussed in detail under each of the sub-questions below.

\subsection{What are the challenges of mentoring beginning teachers in an interme diate context?}

Data was collected, gathering the perspectives from all those involved in the mentoring process in order to identify the challenges of mentoring beginning teachers. While those involved in the process explicitly mentioned most of the challenges identified, others became clear through analysis of the data. The main challenges identified are explained below. 


\subsubsection{Differences in vision of mentoring purpose}

The challenges that emerged were all interlinked and the overarching problem, although not mentioned specifically by the participants, became apparent when the data was analysed. This challenge was the differing views of the purpose of mentoring. There did not appear to be any shared vision of mentoring between the mentor teachers, PRTs and principal. Simply put, the principal viewed mentoring as a leadership opportunity with reciprocal learning opportunities, while the mentor teachers mainly viewed it as extra work that they did not feel qualified for, and the PRTs saw it as a tool for assessment in order for them to meet the criteria for registration. Those involved in the programme seemed unaware of the potential that an effective mentoring has to improve teacher quality, student outcomes and the teaching profession as a whole transforming "schools into vibrant learning communities where both students and their teachers excel” (New Teacher Center, 2013, para. 2). It has been suggested that programmes are most effective when they have a shared vision for success (Moir et al., 2009) and those involved in this study had differing ideas on the purpose of mentoring. These differing perspectives caused other challenges to emerge, such as problems with the selection of mentors and lack of mentor training.

\subsubsection{Unclear procedures}

Five out of the six mentor teachers were not clear on what was expected of them in the role and were also unclear regarding procedures they were meant to follow. One mentor teacher spoke of the fact that there is an assumption that they know what they are doing. With some mentor teachers unaware of where the finish line was, as one PRT put it, mentoring will be unable to fulfil its potential and mentor teachers are more likely to take the default position of working towards something obviously measurable, that of meeting registration, rather than taking a more holistic mentoring approach that is less easily measured. In order for a mentoring programme to be effective it must have guidelines that are clear (Piggott-Irvine et al., 2009; Marable \& Raimondi, 2007; Barrera et al., 2010). Again, the challenge of unclear procedures in the mentoring programme is linked back to the lack of a shared purpose. With a shared purpose, procedures would be able to be explicit and teachers would have goals to enable them to be clear about what they were working towards. 


\subsubsection{Lack of effective mentor selection process}

In an intermediate school there are often a high number of PRTs. At NIS during the year this study was conducted there were six PRTs. The high number of PRTs means that there need to be a high number of mentor teachers available. When syndicate leaders are unable to be mentor teachers, the number of available, experienced teachers drops significantly. The principal commented that she felt restricted by the rule that says a mentor teacher can only be paid once for the role of mentor teacher, even if they are mentoring two PRTs, as was the case at NIS in 2012.

Often it can be hard to recruit mentors, and three of the mentor teachers chosen in 2012 had not volunteered for the role and would rather have not done it. This problem of lack of interest in becoming a mentor is linked back to the lack of a shared purpose for the mentoring programme. If experienced teachers were aware of the potential that the mentoring programme had and viewed mentoring as a leadership opportunity, more teachers may wish to become mentor teachers. The PRTs made the suggestion that the programme should have:

Better quality mentor teachers, that actually have an interest in being mentor teachers.

When there are not enough mentor teachers available the wrong people can get put in the role. Another PRT said:

All mentors are not equal. Since it has such an impact on a PRTs ability to get registered, there needs to be some kind of effort to make sure only the best-suited staff become mentors.

In terms of the sort of person who makes a good mentor one PRT said:

Someone who has some experience, is confident in their abilities, willing to share and find out answers with you.

Choosing the wrong person for the position of mentor is likely to lead to a failure on the part of the mentoring programme and it is essential to select the right teachers for the role. Multiple mentoring can be a successful strategy and the needs of each individual can be met when one mentor works with several mentees at a time (Sweeny, 2008). One of the most important aspects of mentor selection found by Rippon and Martin (2006) was that the mentor wanted to be a mentor, and the 
beginning teachers spoke of mentoring relationships suffering when the mentor was forced into the role. It is the first priority of a mentoring programme to select the most talented mentors (Moir et. al, 2009) and the success of the programme depends on having the right people for the job.

\subsubsection{Untrained mentors}

Although there is no formal requirement from the NZTC for mentor teachers to be trained, professional development in educative mentoring seems necessary as those involved in the process perceived they were using educative mentoring strategies, however, this is unlikely without specific training. The Guidelines state that mentor teachers require training to become mentor teachers, although no mentor teachers in this study had taken part in any. At the start of the year, they were shown the educative mentoring booklets (NZTC, 2011a) and had an opportunity to discuss the guidelines with their PRT. In their study of mentoring programmes, Piggott-Irvine et al. (2009) found the mentors wanted more support and professional development. All mentor teachers in this study wanted professional development to improve their mentoring skills; this is discussed in more detail in 5.2.3.

\subsection{What needs to happen to enable effective mentoring to occur?}

Once the barriers were identified, the study looked to establish what needed to happen to overcome these barriers and enable effective mentoring to occur. From examining both the findings and the literature, these have been identified as necessary conditions for an effective mentoring programme to occur: communication of the purpose of mentoring; leadership of the mentoring programme; effective mentor selection process; ongoing professional development for mentors; and basing the programme in a community of support.

\subsubsection{Communication of the purpose of mentoring}

For mentoring to be effective, not only do mentors need to have a clear idea of what they are doing, but also the school itself needs to be very clear about the purpose and the scope of mentoring (Garvey \& Alred, 2010). It is very important to communicate the mentoring purpose and expectations with mentor teachers and PRTs at the start of the year. Mentor teachers discussed the need for an induction process before the school year begins, with one saying they would rather be overloaded with information than not have any. One mentor teacher pointed out the need for deeper information 
and the importance of the person in charge communicating that information.

At the moment, those involved do not appear to see the potential the mentoring programme has for improving teacher quality and student outcomes. The person appointed to lead the programme and/or the principal would need to make sure those involved were all aware of the programme's potential and purpose. Ensuring those involved are clear on the potential and purpose takes clear and ongoing communication (Moir et al., 2009). If the principal's vision does not align with "the focus of the work between mentors and new teachers, then mentors and principals may work at cross purposes and undermine a new teacher's opportunities to succeed” (Moir et al., 2009, p. 168).

PRTs, mentor teachers and the principal all used the term 'tutor teacher' rather than 'mentor teacher' throughout this study. Before the introduction of the educative mentoring guidelines, there was an 'advice and guidance programme' in place, and in this programme the name for the experienced teacher helping PRTs was 'tutor teacher'. The focus of the tutor teacher was assisting the PRT to meet the RTC. The new educative mentoring guidelines indicate a move away from the notion of 'tutor teacher', to the more holistic 'mentor teacher'. This name change is representative of the shift in thinking, and the continued use of the term 'tutor teacher' is perhaps indicative of the fact that the thinking at NIS has not yet shifted towards educative mentoring.

\section{Potential of mentoring}

PRTs and mentor teachers in this study in this did not appear to realise the potential of an effective mentoring programme. At the moment, the main purpose of the role of mentor teacher is seen as helping a PRT to get through their registration process. Although this is part of their role, and possibly is where the PRT's focus is during those first two years of teaching, in terms of their professional development and future as a teacher, mentoring has the potential to play a much greater role than this. PRTs are able to engage in higher level learning during their first years of teaching, moving mentoring away from helping the new teacher cope with the classroom to educative and transformative (Achinstein \& Athanses, 2006). There is a need for the potential of mentoring to be shared with both PRTs and mentor teachers. The vision and purpose need to be very clear and this clarity may encourage other teachers to 
take on the leadership opportunity that mentoring presents. The reciprocity of an effective mentoring relationship is of great benefit to a mentor teacher as well as a mentee, and this needs to be made clear.

\section{Clarity of expectations and procedures}

Another challenge that came through strongly from both the PRTs and the mentor teachers was that of inconsistency between quality of mentors and a lack of awareness of those involved in the programme of the expectations and procedures associated with the it. One mentor teacher said:

[To improve the process we need] a school wide coordinated approach with an agreed set structure. At the moment you are either good or not and it entirely depends on your motivation rather than any requirements or monitoring.

Another area that needs clarifying is the distinction between the roles of syndicate leader and mentor teacher. One mentor teacher spoke of the tension between the two saying:

You can't put a mentor's role into boxes saying this is the syndicate leader's role, whereas this is the mentor teacher's role because mentoring is meant to be holistic.

A decision was made at NIS to keep the roles of syndicate leader and mentor teacher separate, with no syndicate leaders able to take on the role of mentor teacher. The aim was to widen the PRT's community of support, as they would have two people to support them. The principal explained that this was done to try to:

Give our beginning teachers more than one teacher to help spread the culture so it's not like it's our way or the highway.

Support for beginning teachers needs to come from across a whole school community rather than just from pre-determined mentors (Hargreaves \& Fullan, 2000) and distributing the mentoring across the school was an attempt to encourage this.

However, PRTs did not see it like this and one said:

One advantage to having a mentor teacher that is in your syndicate means there's a common understanding of planning, workload, kids etc. I can understand the view of having two people to go to but if that second person (the mentor) isn't adding to what you're doing, then I think it's not working. 
Another PRT spoke of having to explain things to the mentor teacher and that it was easier just to speak to their syndicate leader, as they spent more time with them. This PRT said:

One of the disadvantages is that I have connections with other people so I go to them before her. I go to my syndicate leader because it's easier to explain to them or they were there and they know day to day the goings on.

This can be compared with the view from the principal who said that ensuring PRTs had support from more than one person was:

a deliberate strategy based on feedback from PRTs to have a second person in the school that they could go to.

The PRT appeared to view having two separate people to go to as negative, and tended to just get support from her syndicate leader, whereas the principal saw it as widening the community of support.

Another challenge that emerges when syndicate leaders are unable to take on the role of mentor is that the number of teachers available to choose from decreases. Also, there are benefits to mentor teachers and PRTs being in the same syndicate. One mentor teacher pointed out that when teachers are busy, it is often PRT meetings that get missed. When they work in the same syndicate as their PRT it is easy to catch up on this lost time, but more difficult when they are in a different syndicate.

Hargreaves and Fullan (2000) state that "mentoring practice may fall short of its ideals not because of poor policies or program design but because we fail to regard mentoring as integral our approach to teaching and professionalism” (p. 50). However, this study suggests that it can also fall down due to poor programme design. The programme design in this study was one of the main areas where the mentoring programme was not working well.

\subsubsection{Leadership of the mentoring programme}

It is very important to the success of the mentoring that someone is appointed to lead the programme. One mentor teacher said that they thought the mentoring programme was an afterthought rather than a priority, and having a person lead the programme would make the programme a priority. The principal also agreed that this would be a 
good idea. At NIS, no one person was seen as being in charge of the programme and those involved in the in the study identified this as a barrier.

A strong leader has the ability to “influence the mentoring team's vision, the success of a program's implementation, and the success of the individuals who mentor and ultimately become instructional leaders” (Moir et al., 2009, p. 171). The appointment of a leader to run the programme would increase its chance of being effective. In secondary schools in New Zealand, there is someone (often the Deputy Principal or specialist classroom teacher) who leads the mentoring programme for the PRTs. They assign mentors to PRTs and meet regularly with the PRTs to discuss any issues. They are also the person who conducts the final assessment to decide whether they can put forward their registration as fully registered teacher (Personal Communication, Adrienne McLeod, 20 December, 2012). Currently there is no equivalent role in primary or intermediate schools.

\section{Feedback on the process}

Both the mentor teachers and the PRTs mentioned it would be useful to have the ability to give feedback to the person leading the programme on whether it was effective. One of the mentor teachers mentioned:

[At the moment] it would be hard for the PRTs to say they're not getting the support they need. We need to empower them so they can say if they're not getting the help.

One of the PRTs spoke about a mentor teacher in the past he had and in terms of the relationship not working said:

It took a long time to get the guts to say something, so maybe at the end of term 2 a little survey that goes to the key people who can actively review.

Sweeny (2008) suggests providing feedback at the end of each term. Not only is it important to have a procedure for giving and receiving feedback, but the leader of the mentoring programme needs to understand what high quality mentoring looks like and have the time to give feedback, conduct surveys and gain a realistic view of what is effective (Moir et al., 2009).

\subsubsection{Effective mentor selection process}

The Guidelines for Induction and Mentoring and Mentor Teachers (NZTC, 2011a) 
describe an effective mentor as someone committed to facilitating their mentee's professional growth and who is able to establish a mentoring relationship that is both effective and respectful. Commitment cannot be assumed when teachers are reluctant conscripts. When teachers are told they will be mentor teachers rather than volunteering for the role, there is resistance. One mentor teacher in this situation said:

I haven't been a tutor teacher in the 11 years I've taught and that's been a choice of mine so it [mentoring] has been a struggle this year.

In 2012, three of the mentors selected did not want to take on this role. At NIS, the inability of syndicate leaders to also be mentor teachers has meant that the pool of possible mentor teachers is greatly reduced. Although this decision was made in order to widen the community of support a PRT receives, it seems that it may be more important to have more teachers to choose from. The PRTs all spoke of the importance of recruiting mentors who want to take on the role, and selecting the best quality mentors. The principal made the point that:

When you look at the demographic of our staff at the moment we are unbalanced in terms of younger teachers to older.

This lack of demographic balance can add to problems with mentor recruitment. In cases like this, an option is the use of full time mentors or retired teachers as in some Californian mentor programmes (Thornton, 2013). The best mentors are outstanding educators who have "exceptional interpersonal skills, being lifelong learners, having the respect of peers, having a history of advocacy etc" (Moir et al., 2009, p. 194). An effective mentor views learning as a transformational process (Carter \& Francis, 2001) and enables their mentee to become the best teacher they can be (Pitton, 2006). The mentor also needs to be an experienced, fully registered teacher who is able to conduct reflective learning conversations and offer guidance, support and give effective feedback (NZTC, 2011a). As the role of mentor is challenging, it is essential to have the right people taking on the position.

By communicating the vision of mentoring and the potential of the programme, more teachers may want to be a part of it. Sweeny (2008) puts forward the idea of marketing the mentoring programme in order to attract mentors. He suggests having a pool of trained mentors to choose from each year to match up with appropriate beginning teachers. If teachers are made aware of the benefits and potentials of 
mentoring, more teachers may volunteer.

\subsubsection{Ongoing professional development for mentors}

None of the mentors in this study had undergone any training, and PRTs and mentors both mentioned the importance of training in order to become effective. Although this did not come up during the focus group session with the mentor teachers, in the survey it came through very strongly. Suggestions for professional development to help mentors develop their skills included:

Giving training in coaching conversations/reflective questioning; and

Get shown ways to challenge them [PRTs] further, beyond the great skills they already have.

The suggestion of learning new ways to challenge the PRTs fits in with the principal's view of mentoring as well as with educative mentoring. Finding a balance between support and stretch is an endemic challenge for educative mentoring (Feiman-Nemser, 2003) and mentors need to be taught this skill.

Effective mentoring requires skills that need to be taught, and it cannot be assumed that an effective teacher is an effective mentor. Moir et al. (2009) highlight the fact that mentoring requires "entirely new skills, and it takes time, sophisticated training, and ongoing coaching and reflection to develop them” (p. 34). In order to mentor in an educative way, mentors require "opportunities to clarify their vision of good teaching, to see and analyze effective models of mentoring, to develop skills in observing and talking about teaching in analytic, nonjudgmental ways, and to learn to assess new teachers' progress and their own effectiveness as mentors” (FeimanNemser, 2003, p. 28). These requirements may be fulfilled through mentors meeting up and discussing their own mentoring relationships, observing each other during mentor meetings and co-constructing ways of assessing their own effectiveness.

A possibility for ongoing professional development is a mentor academy where the mentors participate in a learning community (Moir et al., 2009). Another large Wellington intermediate school created a mentoring cluster with other schools in the area in 2011. Over the course of the year they met regularly and employed trainers to come in and work with the mentor teachers. This only lasted one year due to lack of 
funding (Marian Williams, personal communication, 10 November 2012). Mentor academies could be a cost efficient way of providing training for mentors from different schools at the same time. As mentors are not born, but rather are made, the process of becoming a mentor is continuous (Achinstein \& Athanases, 2006) and professional learning needs to be ongoing.

\subsubsection{Based in a community of support}

One PRT mentioned that she went to her syndicate leader before her mentor teacher for assistance. She did this because it was easier going to her syndicate leader due to proximity (she was in the classroom next door) and the fact her syndicate leader knew the context of what was happening in the classroom. The informal conversations that happen between syndicate leader and teacher are very useful in offering assistance to a PRT, but could be thought of as part of the community of support rather than the syndicate leader taking on the role of mentor teacher. It may also be an argument for allowing syndicate leaders to become mentor teachers, as the informal meeting between mentor and mentee has more impact than the formal meeting (Spindler \& Biott, 2000), and this adds to the strength of the mentoring relationship. For mentoring programmes to be successful they need to be based within a community of support. This means a collaborative environment where PRTs get support from multiple members of the learning community and where professional conversations are the norm (Piggott-Irvine et al., 2009).

Piggott-Irvine et al. (2009) found that at schools that had successful mentoring programmes, the PRTs had access to a wide community of support throughout the school that extended beyond the mentoring relationship. Research has shown that mentoring is more effective when it takes place within schools that have a strong learning culture (Hobson et al., 2009). As part of this strong learning culture, it is important to value the knowledge that all members of the community have, including PRTs, and schools that do this are most successful in retaining teachers (Long, 2009).

\subsection{How does the tension between assistance and assessment affect the mentoring relations hip?}

The study uncovered an interesting tension between assessment and assistance within the educative mentoring framework. On paper, educative mentoring seems like the most effective way to mentor. However, in the New Zealand system where teachers 
are required to meet criteria to achieve full teacher registration and the mentor teacher is the person who decides whether the criteria are met, there is a tension that emerges for the mentor as both assistance provider and assessor. The tension this creates is discussed below.

\subsubsection{The tension of assessment}

Tension between assistance and assessment within mentoring exists throughout the teaching profession. The challenge is to recognise this and for mentors to establish how to "enact a sensitive but dynamic and shifting balance between the two" (Bullough, 2012, p. 68). Mentor teachers are most able to do this when the PRT is based in a community of support and when the mentor is "recognized and respected as a fully engaged community member” (Bullough, 2012, p. 68). However, it is the mentor teachers who are mainly responsible for the registration of their beginning teacher. In order to gain full registration PRTs need to complete the set amount of teaching service and meet the Registered Teacher Criteria (NZTC, 2011b). Educative mentoring and the new guidelines for mentoring have a focus on assistance (NZTC, 2011a), although the mentor teacher is responsible for deciding whether the PRT meets the criteria set out by the NZTC for the full registration of teachers. However, in secondary schools, it is the person who leads the PRT programme who decides whether the teacher meets the registered teacher criteria. This appears to take the assessment aspect out of the mentoring relationship and may be a solution to this tension between assistance and assessment. Meeting the criteria should be part of the mentoring process, as some accountability is necessary from the NZTC's point of view, but this should occur naturally as part of the mentoring process.

\subsubsection{Diffe ring perspectives}

The three different groups involved in the mentoring process at NIS seemed to see the balance between assistance and assessment as lying in different places. The PRTs seemed to perceive the mentoring process as having the most emphasis on assessment, the mentor teachers appeared to be in the middle and the principal seemed more focused on the professional development of the PRT and the development of leadership skills of the mentor teacher. See Figure 2. 
Figure 4: Perceptions on where the balance lies between assistance and assessment

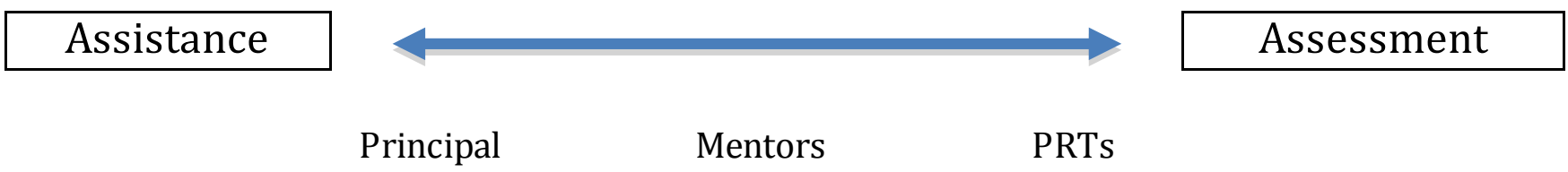

This comment by a PRT illustrates their belief that their mentoring relationship should have a focus on assessment:

Isn't the purpose of the tutor teacher to get you through the registration? When talking about an effective mentor, one PRT said:

She is definitely doing it cause she wants to get us through the process. Because she's only a couple of years out she has a really good understanding of the paper trail.

Another added that their mentor teacher:

Is a 'paper person', which is what's needed.

Five out of the six PRTs wanted a focus on assessment in their mentoring relationship. The PRTs were happy with the mentoring because it was currently supportive rather than challenging. They appeared to want quick meetings that fulfil a purpose and help them meet their registration. Two of the PRTs spoke about how important they believed recent experience in the process of teacher registration is to the role of mentor teacher, suggesting they become mentor teachers next year as third year teachers. One of these PRTs said:

We're open to being tutor teachers, because we've just been through it. The experience in the PRT process is probably more important than experience teaching for a tutor teacher.

This indicates a focus on the process of meeting criteria rather than improving teaching practice, which does not fit in with educative mentoring and the transformative approach to mentoring. 
The principal also mentioned the tension between experience and those recently becoming registered being one of the challenges of mentor selection, saying that she does favour the younger teachers being mentor teachers as they have most recently been through the process. Again this is linked to differing perspectives on the purpose of the mentoring programme. If the purpose of the mentoring programme is just to get a teacher through their registration, then it would be a good idea to have third-year teachers as mentors. However, educative mentoring is about much more than this and Moir et al. (2009) suggest no less than five years' experience for mentors as well as extensive professional development.

The relationships between mentor and PRT appeared as a strength of the mentoring process in this research and indeed relationship is key to an effective mentoring process. While it is essential that the relationships are successful, it also means the PRT's perceptions of how well the mentor is implementing the high level of educative guidelines data may not have been accurate. The survey results showed that PRTs perceived their mentors as being effective, although it is unlikely that they are performing at the high level that is recommended by the guidelines (without any training or professional support). The findings from the survey could be because of the positive relationships they had, or because the PRTs wanted the focus of their meetings to be on assessment, and the higher-level thinking that is part of educative mentoring was not a priority for them. PRTs were happy because essentially all they wanted is assurance they were on track for getting their registration. This indicates a gap between the perceptions of effective mentoring and the higher level of mentoring that is possible with educative mentoring.

\section{A focus on assessment}

Although the PRTs in this study identified their main goal for the mentoring relationship was for their mentor to get them through registration, this might have been a result of not being aware of the potential of a mentoring programme and the fact they are already in a high community of support. In an intermediate school, everyone teaches the same level and the opportunities for collaboration and support are greater than in a primary school where staff may be focussed on their own specific teaching level. Teaching at the same year level means there is much collaboration between teachers and this allows a community of high support to develop organically across the school. In a school that has this high support and relevant ongoing 
professional development, it is possible that PRTs are getting the support and challenge that is needed from educative mentoring outside their mentoring relationship. This may mean that do not rely on their mentor as much as PRTs in a school that does not have this high level of support. It is possible that PRTs at NIS are in this situation and get the pedagogical support and challenge from outside their mentoring relationship and therefore only require their mentor for registration purposes.

\subsection{Summary}

This chapter has identified challenges to implementing the educative mentoring guidelines and described the conditions that need to be in place to enable effective mentoring to occur. The biggest challenge identified was the lack of shared understanding of the mentoring programme, and the other issues arose as a result of this. It has discussed the tension that exists between assistance and assessment. Although none of the mentors or PRTs in this study mentioned the tension between assistance and assessment, this was possibly due to the fact that they were unaware of the potential of educative mentoring and the PRTs were focussed on the assessment aspect. Once those involved are made aware of the potential, the new challenge of negotiating this balance may emerge.

With such a steep learning curve during the first two years of teaching, the idea of having to also take part in an intensive mentoring programme may not necessarily be appealing to PRTs. However, a good mentor would see this and be able to adapt the support and challenge balance to fit in with the PRT's needs. As Rippon and Martin suggest: "the best mentors are those who can negotiate their way through the shifting sands of support at the right time for each person” (2006, p.86). 


\section{Chapter Six: Conclusion}

\subsection{Introduction}

This concluding chapter identifies recommendations that have been made to NIS as a result of the findings of the study and the literature and discusses opportunities for further research that have become apparent. The research question asked how effectively educative mentoring guidelines were being implemented in an intermediate school. In this case, it appeared that there was one main challenge being faced that meant educative mentoring was not occurring to its potential.

The biggest challenge to this educative mentoring programme was a lack of shared understanding of its purpose. The PRTs believed the purpose of a mentoring programme was assessment, helping them to achieve their full teaching registration. The mentor teachers were aware of the importance of assessment in helping the PRT meet the RTC, but felt unqualified to take on the more holistic role of mentor. The principal viewed mentoring as an educative process and leadership opportunity for the mentor teacher, where both mentor and PRT benefit.

As there was a lack of shared purpose, the goal of the programme appeared different to all involved in the process. This made it difficult to achieve the vision set out by the guidelines of an educative mentoring programme that is both transformative to the teaching profession and the individual teacher's practice. It also resulted in confusion around procedures and expectations, and inconsistency in delivery by mentor teachers. With a shared purpose, everyone involved in the process would be able to work together towards an effective, educative mentoring programme.

The lack of shared purpose led to other challenges being faced in the implementation of the educative mentoring guidelines. Mentor teachers did not see the role as a leadership opportunity, and felt it was extra work they were unqualified for. Mentor selection was difficult due to being unable to choose syndicate leaders for the role, and lack of willing suitable mentors. The lack of a programme leader meant that the programme seemed an afterthought and not enough time and attention was given to developing the knowledge of educative mentoring. PRTs mainly wanted assurance of meeting criteria, and it is unlikely their practice transformed as a result of being involved in the programme. It seemed as though the whole point of educative mentoring was missed, and more work needed to be done in educating both mentors 
and PRTs in the potential of an effective educative mentoring programme.

\subsection{Recommendations}

This study recommends that schools appoint a programme leader to lead and oversee the mentoring process at the school. The programme leader would be able to work together with those involved in the mentoring programme to develop a shared vision of the purpose and goals of mentoring, ensuring PRTs and mentor teachers all understood what was involved in educative mentoring.

As a result of analysing the data collected in this study and the current literature around mentoring, it has become apparent that the role of programme leader requires a large amount of work. Schools in New Zealand are currently restricted in terms of paying mentor teachers. They can only be paid once, even if they are mentoring more than one PRT. Mentor teachers are also classroom teachers and have other priorities in a school other than their mentoring role. In order to enable the mentoring programme to reach its potential as a transformative strategy that increases teacher quality and student achievement, an option here would be to have one programme leader and mentor across a cluster of schools as seen in California. The Ministry of Education could create a new role for one programme leader/mentor, across a number of schools in one area who organises the mentor training and oversees the process at all the schools in the area. This would give the mentoring programme its best chance at success.

\subsection{Opportunities for further research}

This study has only looked at the mentoring programme within one intermediate school. It would add more to the understanding of mentoring programmes if perceptions of PRTs in a number of intermediate schools were examined and analysed. It would also be of interest to establish whether schools with high support and structure view their mentoring programme as one of assessment more than assistance. As there is not yet any published literature around the implementation of the educative guidelines in New Zealand schools, research on this could be carried out to identify other challenges and assist further with implementation. It would deepen the knowledge of implementation of the guidelines to examine the differences faced by primary schools and intermediate schools and identify in more detail the similar issues each are facing. 


\subsection{Summary}

This case study has shown the challenges of implementing the educative mentoring guidelines at an intermediate school, and recommended ways to overcome these challenges. It has highlighted the importance of selecting the best mentor teachers, training those mentors effectively and ensuring everyone involved in the mentoring process has a clear idea of the purpose of the programme and the procedures and expectations. This study recommends that New Zealand looks to employ external mentors, as happens currently in California, in order to give the programme the attention it deserves. If mentoring is to be taken seriously as a strategy for improving teacher quality and student achievement, then the role of programme leader is too great for the classroom teacher. If we wish to build a "competent, committed, and reflective teaching force to carry our schools forward, it will require exemplary mentoring programs” (Helman, 2006, p. 82). The development of the educative mentoring guidelines in New Zealand was a step in the right direction for the future of mentoring, and now it is time to take the next step forward towards building an exemplary mentoring programme that fosters and encourages PRTs, develops exceptional mentors and improves the teaching profession as a whole. 


\section{Reference List:}

Achinstein, B. \& Athanases, S. (2006). New vision for mentoring new teachers. In B. Achinstein \& S. Athanases (Eds). Mentors in the making: Developing new leaders for new teachers (pp. 23-37). New York, NY: Teachers College Press.

Aitken, H., Bruce Ferguson, P., McGrath, F., Piggot-Irvine, E., \& Ritchie, V. (2008). Learning to teach. Success case studies of teacher induction in Aotearoa New Zealand. Wellington: New Zealand Teachers Council.

Angelle, P. (2006). Instructional leadership and monitoring: Increasing teacher intent to stay through socialization. NASSP Bulletin, 90(4), 318-334.

Barrera, A., Braley, R., \& Slate, J. (2010). Beginning teacher success: an investigation into the feedback from mentors of formal mentoring programs. Mentoring \& Tutoring: Partnership in Learning. 18(1), 61-74.

Braun, V. \& Clarke, V. (2006) Using thematic analysis in psychology. Qualitative Research in Psychology,3(2), 77-101.

Britton, T., Raizen, S., Paine, L., \& Huntley, M. A. (2000). More swimming, less sinking: Perspectives on teacher induction in the U.S. and abroad. http://www.wested.org/online_pubs/teacherinduction/.

Bullough, R., (2012): Mentoring and New Teacher Induction in the United States: A Review and Analysis of Current Practices, Mentoring \& Tutoring: Partnership in Learning, 20:1, 57-74.

Cain, T. (2009). Mentoring trainee teachers: how can mentors use research?, Mentoring \& Tutoring: Partnership in Learning, 17(1), 53-66.

Cameron, M., Dingle, R., and Brooking, K. (2007). Learning to teach - A survey of provisionally registered teachers in Aotearoa New Zealand. Wellington: New Zealand Council of Educational Research. 
Carter, M., \& Francis, R. (2001). Mentoring and Beginning Teachers' Workplace Learning. Asia-Pacific Journal Of Teacher Education,29(3), 249-262.

Carver, C. \& Feiman-Nemser, S. (2009). Using policy to improve teacher induction: critical elements and missing pieces. Educational Policy, 23(2), 295-328.

Clutterbuck, D. \& Megginson, D. (Eds). (1995). Mentoring in action. London: Kogan Page.

Coghlan, E \& Brannick, T. (2010). Doing Action Research in Your Own Organization. $\left(3^{\text {rd }}\right.$ ed.) Sage.

Cohen, L., Manion, L., \& Morrison, K. (2011). Research Methods in Education. (7 ${ }^{\text {th }}$ ed.). London: RoutledgeFalmer.

Darling-Hammond, L. (2003). Wanted: A National Teacher Supply Policy for Education: The Right Way to Meet the "Highly Qualified Teacher”. Education Policy Analysis Archives, 11(33).

Denscombe, M. (2003). The Good Research Guide for small-scale social research projects. ( $2^{\text {nd }}$ ed.). Open University Press. England.

Denzin, N. \& Lincoln, Y. (Eds.). (2008). The SAGE handbook of qualitative research. Sage Publications, Incorporated.

Dinham, S. \& Rowe, K. (2008) Teaching and Learning in Middle Schooling: A Review of the Literature. Ministry of Education. New Zealand.

Douglas, C. (1997). Formal mentoring programs in organizations. Greensboro, N.C.: Center for Creative Leadership. 
Evertson, C. \& Smithey, M. (2000). Mentoring effects of protégés’ classroom practice: An experimental field study. Journal of Educational Research, 93(5), 294-304.

Feiman-Nemser, S., \& Parker, M. (1993). Mentoring in Context: A Comparison of Two US Programs for beginning teachers. International Journal of Educational Research, 19(8).

Feiman-Nemser, S. (2003). What new teachers need to learn. Educational Leadership, 60(8), 25-29.

Garvey, B. \& Alred, G. (2010). Education mentors. Mentoring and Tutoring, 8(2), 113-126.

Gillham, B. (2003). Case Study Research Methods. Continuum: London.

Gless, J. (2006). Designing mentoring programs for transforming school cultures. In B. Achinstein \& S. Z. Athanases (Eds.), Mentors in the making: Developing new leaders for new teacher (165-176). New York, NY: Teachers College Press.

Hargreaves, A., \& Fullan, M. (2000). Mentoring in the new millennium. Theory into Practice, 39, 50-56.

He, Y. (2009). Strength-based mentoring in pre-service teacher education: a literature review. Mentoring \& Tutoring: Partnership in Learning, (17)3. 263-275.

Helman, L. (2006). What's in a conversation? Mentoring stances in coaching conferences and how they matter. In B. Achinstein \& S. Athanases (Eds). Mentors in the making: Developing new leaders for new teachers (pp. 69-82). New York, NY: Teachers College Press.

Hinchey, P. H. (2008). Action research primer. Peter Lang Inc Pub. 
Hobson, A., Ashby, P., Malderez, A., \& Tomlinson, P. (2009). Mentoring beginning teachers: What we know and what we don't. Teaching and Teacher Education, 25, 207-216.

Howe, E. (2006). Exemplary teacher induction: An international review. Educational Philosophy and Theory, 38(3), 287-297.

Ingersoll, R. \& Strong, M. (2011). The impact of induction and mentoring programs for beginning teachers: A critical review of the research. Review of Educational Research. 82(2), 201-233.

Ingwalson, G., \& Thompson, J. (2007). A tale of two first-year teachers: One likely to continue, one likely to drop out. Middle School Journal,39(2), 43-49.

Johnson, B., \& Christensen, L. (2012). Educational Research: Quantitative, Qualitative, and Mixed Approaches. SAGE Publications, Inc. Los Angeles, CA.

Langdon, F. (2011). Shifting perception and practice: New Zealand beginning teacher induction and mentoring as a pathway to expertise, Professional Development in Education, 37(2), 241-258.

Langdon, F. with Flint, A., Kromer, G., Ryde, A., \& Karl, D. (2011). Induction and mentoring pilot: Primary. Leading learning in induction and mentoring. New Zealand Teachers Council.

Lieberman, A., Hanson, S., Gless, J. (2012). Mentoring Teachers: Navigating the Real-World Tensions. The New Teacher Center. Jolley-Bass. CA.

Little, J. (1990). The mentor phenomenon and the social organization of teaching. Review of Research in Education, 16, 297-351.

Long, J. (2009). Assisting beginning teachers and school communities to grow through extended and collaborative mentoring experiences, Mentoring \& Tutoring: Partnership in Learning, 17(4), 317-327. 
Long, J., McKenzie-Robblee, S., Schaefer, L., Steeves, P., Wnuk, S., Pinnegar, E., \& Clandinin, D. (2012): Literature Review on Induction and Mentoring Related to Early Career Teacher Attrition and Retention, Mentoring \& Tutoring: Partnership in Learning, 20(1), 7-26.

Maynard, T. (2000) Learning to Teach or Learning to Manage Mentors? Experiences of school-based teacher training, Mentoring \& Tutoring: Partnership in Learning, 8(1), 17-30.

Marable, M., \& Raimondi, S. (2007). Teachers' perceptions of what was most (and least) supportive during their first year of teaching. Mentoring \& Tutoring, Partnership in Learning 15(1), 25-37.

McDonald, L. \& Flint, A. (2011). Effective Educative Mentoring Skills: A Collaborative Effort. New Zealand Journal of Teachers’ Work, 8(1), 33-46.

Merriam, S. (1998). Qualitative Research and Case Study Applications. San Francisco, CA: Jossey-Bass Publishers.

McNiff, J \& Whitehead, J. (2010). You and Your Action Research Project. Routledge: Oxon.

Moir, E. (2012). Forward. In Lieberman, A., Hanson, S., Gless, J. Mentoring Teachers: Navigating the Real-World Tensions. The New Teacher Center. Jolley-Bass. CA.

Moir, E., Barlin, D., Gless, J., \& Miles, J. (2009). New teacher mentoring: Hopes and promises for improving teacher effectiveness. Cambridge, MA: Harvard Education Press.

Moir, E., \& Bloom, G. (2003). Fostering leadership through mentoring. Educational. Leadership, 60(8), 58-60. 
Moir, E., \& Gless, J. (2001). Quality induction: an investment in teachers. Teacher Education Quarterly, 28(1), 109-115.

Murphy, K., Mahoney, S., Chen, C., Mendoza-Diaz, N., Xiobaing. (2005). A constructivist model of mentoring, coaching and facilitating online discussions. Distance Education, 26(3).

New Zealand Teachers Council. (2010). Registered Teacher Criteria handbook. Wellington: New Zealand Teachers Council.

New Zealand Teachers Council. (2011a). Professional Learning Journeys: Guidelines for Induction and Mentoring and Mentor Teachers. Learning Media. Wellington.

New Zealand Teachers Council. (2011b). Towards Full Registration: A Support Kit. Learning Media. Wellington.

New Zealand Teachers Council. (2013a). Welcome to New Zealand Teachers Council. http://www.teacherscouncil.govt.nz/.

New Zealand Teachers Council. (2013b). Application to gain full teacher registration. http://www.teacherscouncil.govt.nz/pubres/forms/tc2webform.pdf.

Norman, P. \& Feiman-Nemser, S. (2005). Mind activity in teaching and mentoring. Teaching and Teacher Education 21(6), 679-697.

NTC. (2013). CEOs message. http://www.newteachercenter.org/about-ntc/ceosmessage.

NZCER. (2013). Impact of education reforms. http://www.nzcer.org.nz/research/impact-education-reforms.

NZARE. (2010). Ethical guidelines. http://www.nzare.org.nz/pdfs/NZAREEthicalGuidelines2010.pdf. 
O’Leary, Z. (2010). The Essential Guide to Doing Your Research Project. London: Sage.

Parsloe, E. \& Wray, M. (2000). Coaching and Mentoring: practical methods to improve learning. London: Kogan Page.

Patton, M. (2002). Qualitative research and evaluation methods (3rd ed.). Thousand Oaks, CA: Sage.

Piggott-Irvine, E., Aitken, H., Ritchie, J., Ferguson, P., \& McGrath, F. (2009). Induction of newly qualified teachers in New Zealand. Asia Pacific Journal of Teacher Education, 37(2), 175-198.

Pitton,D. (2006). Mentoring Novice Teachers: Fostering a Dialogue Process. Thousand Oaks: Corwin Press.

Punch, K.F. (2005). Introduction to social science research: Quantitative and qualitative approaches ( $2^{\text {nd }}$ ed.). London: Sage.

Rippon, J. \& Martin, M. (2006). What makes a good induction supporter? Teaching and Teacher Education, 22(1), 84-99.

Roberts, A. (2000). Mentoring Revisted: A phenomenological reading of the literature. Mentoring \& Tutoring: Partnership in learning, 8(2), 145-170.

Robson, C. (2002). Real World Research. ( $2^{\text {nd }}$ ed.). Blackwell Publishers Inc: USA.

Roehrig, A, Bohn, C, Turner, J \& Pressley, M. (2007). Mentoring beginning primary teachers for exemplary teaching practices. Teaching and Teacher Education, 24, 684-702. 
Shinners, R. \& Sweetland, J. (2008). . Inspired issue brief: investing in teachers through mentoring. Center for Inspired Mentoring. http://www.inspiredteaching.org/wp-c ontent/uploads/impact-research-briefsmentoring.pdf.

Smith, T. \& Ingersoll, R. (2004). What are the effects of induction and mentoring on beginning teacher turnover. American Educational Research Journal, 41(3), 681714.

Spindler, J. \& Biott, C. (2000). Target setting in the induction of newly qualified teachers: emerging colleagueship in a context of performance management. Educational Research, 42(3), 275-285.

Street, C. (2004). Examining learning to teach through a social lens: How mentors guide newcomers into a professional community of learners. Teacher Education Quarterly, 31(2), 7-24.

Sweeny, B. (2008). Leading the Teacher Induction and Mentoring Program ( $2^{\text {nd }}$ ed.). Thousand Oaks, CA: Corwin Press.

Thornton, K. (2013). Educative mentoring in the New Zealand context: next steps. Manuscript submitted for publication.

Wang, J., \& Odell, S. (2002). Learning to teach according to standards-based reform: A Critical Review. Review of Educational Research, 72(3), 481-546.

Waterman, S. \& He, Y. (2011). Effects of mentoring programs on new teacher retention: a literature review. Mentoring \& Tutoring:Partnership in Learning, 19(2), 139-156. 
Whisnant, E., Elliott, K. \& Pynchon, S. (2005). A review of literature on beginning teacher induction. http://www.cstpwa.org/sites/default/files/A_Review_of_Literature.pdf.

Yin, R. (2009). Case Study Research: Design and Methods. (4th ed.). California: Sage Publications.

Yusko, B., \& Feiman-Nemser, S. (2008). Embracing contraries: Combining assistance and assessment in new teacher induction. The Teachers College Record,110(5), 923-953. 
Appendices 


\section{Appendix A}

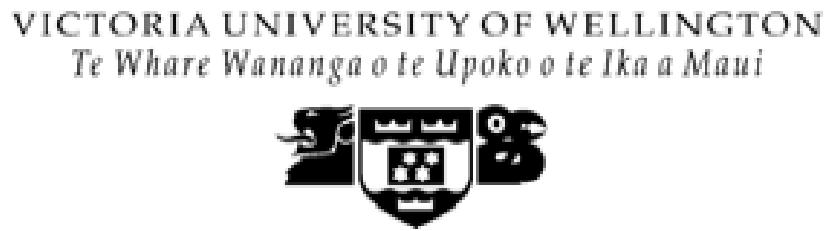

Faculty of Education

Research project: Mentoring beginning teachers within an intermediate setting

Information Sheet for current Mentor Teachers

Researcher: Sarah Patterson

I am wishing to conduct research at school on the mentoring of beginning teachers as part of my Masters of Education study. The aim of the project is to evaluate the current state of mentoring practice and identify areas for improvement, with two workshops to up-skill mentor teachers in the areas identified.

As part of this research I am seeking the participation of current mentor teachers. If you choose to participate, your participation will consist of:

- Completion of an anonymous online survey (approximately 5-10 minutes)

- Possible focus group session (30 mins)

- Two one-hour workshops conducted during Wednesday morning development learning time

- Observation of one PRT meeting (voluntary)

- Completion of a second anonymous online survey (approximately 5-10 minutes).

A link to the online survey will be emailed out to you upon receiving your consent form. You will be asked to pick a 4-digit number when completing the survey. This is to track the difference between your answers at the start of the study and your answers at the end of the study and in no way identifies your responses.

It is possible there will be a focus group session to gain clarity around the data received from the initial survey but you will be informed of this following the initial survey. There will be two one-hour workshops run during Wednesday morning PD sessions designed to improve mentoring practice following the results of the initial survey. I am also asking for volunteers to be observed during one PRT meeting. The purpose of the observation is to find out whether strategies from the workshop are being implemented. Neither the school nor you will be identified in the thesis and pseudonyms will be used. However if you choose to have your PRT meeting observed you should be aware that only three of these observations will take place and you may be recognisable to others who 
have participated in the study. If there are more than three volunteers for the observation, random selection will be used to choose the participants. Your participation in this project will conclude with your completion of the online survey.

Your participation is voluntary and you are under no obligation to agree to be a part of it. Should you feel the need to withdraw from the project, you may do so without question at any time before the data is analysed. You will be offered a copy of the summary of the study once it is completed.

Victoria University requires that ethics approval be obtained for research involving human participants. This research has been assessed and approved by Victoria University Faculty of Education Ethics Committee. Responses collected will form the basis of my research project and will be put into a written report on an anonymous basis. Only grouped responses will be presented in this report. All material collected will be kept confidential. No other person besides my supervisor, Dr Kate Thornton, and I will see the surveys or transcripts of discussions. The thesis will be submitted for marking and deposited in the University Library. It is intended that one or more articles will be submitted for publication in scholarly journals. Surveys and transcripts will be destroyed five years after the end of the project.

If you have any questions or would like to receive further information about the project, please contact me (charlieandsarah@xtra.co.nz) or my supervisor, Dr Kate Thornton (kate.thornton@vuw.ac.nz), at the School of Educational Policy and Implementation at Victoria University, PO Box 600, Wellington, phone 4639776.

If you agree to participate, please fill in and sign the form and hand it back to Lucy by Friday 22 June.

Kind regards

Sarah Patterson 


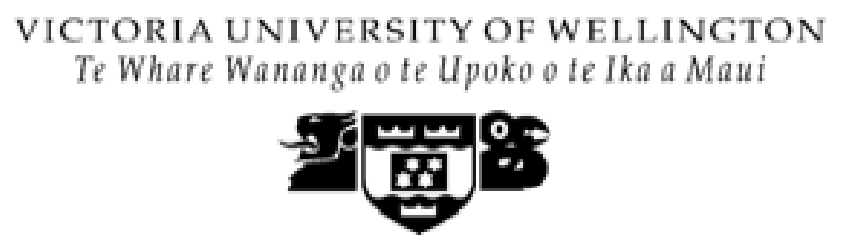

Faculty of Education

Research project: Mentoring beginning teachers within an intermediate setting

Consent form for mentor teachers

[Please mark each box with a tick to indicate agreement, then sign and date this form]

I have been given and have understood an explanation relating to the nature and purpose of this research project. I have had an opportunity to ask questions about it.

I give permission for the researcher to collect data through an online survey.

I give permission for the researcher to conduct an observation during a meeting with my PRT (if currently a mentor teacher).

I give the researcher permission to collect data through a focus group discussion.

I understand that the data collected will be keptsecure. Only the researcher and a supervisor will have access to the data. I also understand that all the data collected will be destroyed 5 years after the conclusion of the study.

I understand that my name will not be revealed in any publication arising from this research, instead pseudonyms will be used.

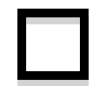

I understand that the research may be presented in academic or professional journals.

I understand that I can withdraw from this study without giving a reason up until the conclusion of the data collection.

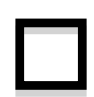

Name

Signature

Date

\section{Appendix B}




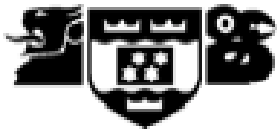

Faculty of Education

Research project: Mentoring beginning teachers within an intermediate setting Information Sheet for past Mentor Teachers

Researcher: Sarah Patterson

I am wishing to conduct research at school around the mentoring of beginning teachers as part of my Masters of Education study. The aim of the project is to evaluate the current state of mentoring practice and identify areas for improvement, with two workshops to up-skill teachers in the areas identified.

As part of this research I am seeking the participation of current and past mentor teachers. If you choose to participate, your participation will consist of:

- Completion of an online survey (approximately 5-10 minutes)

- Two one-hour workshops conducted during Wednesday morning professional development time

- Completion of a second online survey (approximately 5 minutes).

A link to the online survey will be emailed out to you upon receiving your consent form. You will be asked to pick a 4-digit number when completing the survey. This is to track the difference between your answers at the start of the study and your answers at the end of the study and in no way identifies your responses.

There will be two one-hour workshops designed to improve mentoring practice following the results of the initial survey. Your participation in this project will conclude with your completion of a short online survey.

Your participation is voluntary and you are under no obligation to agree to be a part of it. Should you feel the need to withdraw from the project, you may do so without question at any time before the data is analysed. You will be offered a copy of the summary of the study once it is completed.

Victoria University requires that ethics approval be obtained for research involving human participants. This research has been assessed and approved by Victoria University Faculty of Education Ethics Committee. Responses collected will form the basis of my research project and will be put into a written report on an anonymous basis. Only grouped responses will be presented in this report. All material collected will be kept confidential. No other person besides my supervisor, Dr Kate Thornton, and I will see the surveys or transcripts of discussions. The thesis will be submitted for marking and deposited in the University Library. It is intended that one or more articles will be submitted for 
publication in scholarly journals. Surveys and transcripts will be destroyed five years after the end of the project.

If you have any questions or would like to receive further information about the project, please contact me (charlieandsarah@xtra.co.nz) or my supervisor, Dr Kate Thornton (kate.thornton@vuw.ac.nz), at the School of Educational Policy and Implementation at Victoria University, PO Box 600, Wellington, phone 4639776.

If you agree to participate, please fill in and sign the consent form and hand it to Lucy by Friday 22 June 2012.

Kind regards

Sarah Patterson 


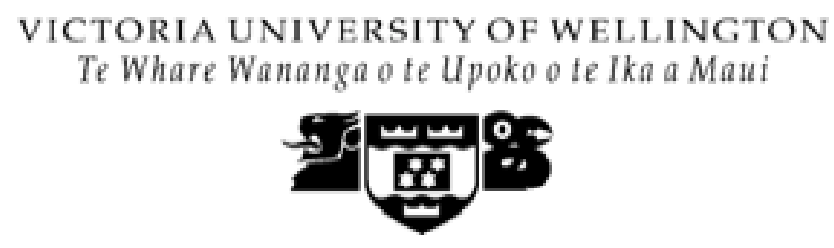

Faculty of Education

Research project: Mentoring beginning teachers within an intermediate setting Consent form for past mentor teachers

[Please mark each box with a tick to indicate agreement, then sign and date this form] I have been given and have understood an explanation relating to the nature and purpose of this research project. I have had an opportunity to ask questions about it.

I give permission for the researcher to collect data through an online survey.

I understand that the data collected will be kept secure. Only the researcher and a supervisor will have access to the data. I also understand that all the data collected will be destroyed 5 years after the conclusion of the study.

I understand that my name will not be revealed in any publication arising from this research, instead pseudonyms will be used.

I understand that the research may be presented in academic or professional journals.

I understand that I can withdraw from this study without giving a reason up until the conclusion of the data collection.

Name

Signature

Date 
Appendix C

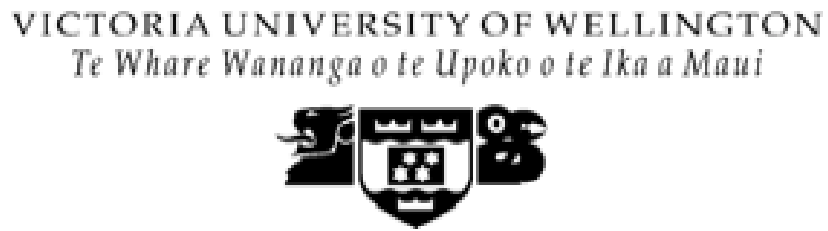

Faculty of Education

Research project: Mentoring beginning teachers within an intermediate setting Information Sheet for Third Year Teachers

Researcher: Sarah Patterson

I am wishing to conduct research at school around the mentoring of beginning teachers as part of my Masters study. The aim of the project is to evaluate the current state of mentoring practice and identify areas for improvement, with two workshops to up-skill mentor teachers in the areas identified.

As part of this research I am seeking the participation of third year teachers as they have recently completed the induction process and will have valuable knowledge about the mentoring process.

If you choose to participate in this study, your participation will consist of:

- Completion of an anonymous online survey (approximately 5-10 minutes)

A link to the online survey will be emailed out to you upon receiving your consent form.

Your participation is voluntary and you are under no obligation to agree to be a part of it. Should you feel the need to withdraw from the project, you may do so without question at any time before the data is analysed. You will be offered a copy of the summary of the study once the project is completed.

Victoria University requires that ethics approval be obtained for research involving human participants. This research has been assessed and approved by Victoria University Faculty of Education Ethics Committee. Responses collected will form the basis of my research project and will be put into a written report on an anonymous basis. Only grouped responses will be presented in this report. All material collected will be kept confidential. No other person besides my supervisor, Dr Kate Thornton, and I will see the surveys or transcripts of discussions. The thesis will be submitted for marking and deposited in the University Library. It is intended that one or more articles will be submitted for publication in scholarly journals. Surveys and transcripts will be destroyed five years after the end of the project. 
If you have any questions or would like to receive further information about the project, please contact me (charlieandsarah@xtra.co.nz) or my supervisor, Dr Kate Thornton (kate.thornton@vuw.ac.nz), at the School of Educational Policy and Implementation at Victoria University, PO Box 600, Wellington, phone 463 9776.

If you agree to participate, please fill in and sign the consent form and hand it to Lucy by Friday 22 June 2012.

Kind regards

Sarah Patterson 


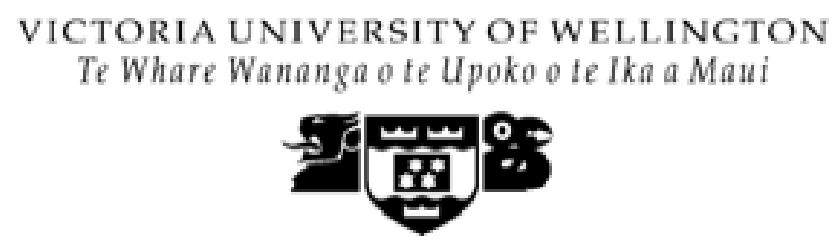

Faculty of Education

Research project: Mentoring beginning teachers within an intermediate setting Consent form for PRTs

[Please mark each box with a tick to indicate agreement, then sign and date this form]

I have been given and have understood an explanation relating to the nature and purpose of this research project. I have had an opportunity to ask questions about it.

I give permission for the researcher to collect data through an online survey.

I understand that the data collected will be kept secure. Only the researcher and a supervisor will have access to the data. I also understand that all the data collected will be destroyed 5 years after the conclusion of the study.

I understand that my name will not be revealed in any publication arising from this research, instead pseudonyms will be used.

I understand that the research may be presented in academic or professional journals.

I understand that I can withdraw from this study without giving a reason up until the conclusion of the data collection.

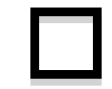

Name

Signature Date 


\section{Appendix D}

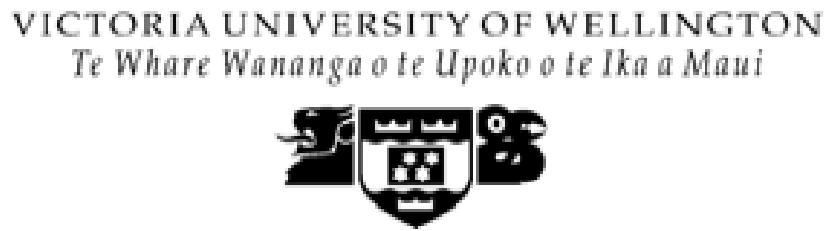

Faculty of Education

Research project: Mentoring beginning teachers within an intermediate setting Information Sheet for Provisionally Registered Teachers

Researcher: Sarah Patterson

I am wishing to conduct research at school around the mentoring of beginning teachers as part of my Masters of Education study. The aim of the project is to evaluate the current state of mentoring practice and identify areas for improvement, with two workshops to up-skill mentors in the areas identified.

As part of this research I am seeking the participation of first and second year Provisionally Registered Teachers. If you choose to participate, your participation will consist of:

- Completion of an anonymous online survey (approximately 5-10 minutes)

- Possible focus group session (30 minutes)

- Two workshops conducted during Wednesday morning professional development time

- Observation of one PRT meeting (voluntary)

- Completion of a second anonymous online survey (approximately 5-10 minutes).

A link to the online survey will be emailed out to you upon receiving your consent form. You will be asked to pick a 4-digit number when completing the survey. This is to track the difference between your answers at the start of the study and your answers at the end of the study and in no way identifies your responses.

It is possible there will be a focus group session to gain clarity around the data received from the initial survey but you will be informed of this following the initial survey. This would take place in the library after school. I am also asking for volunteers to be observed during one PRT meeting. The purpose of the observation will be to see whether the mentor teacher has implemented strategies from the workshops. Neither you nor the school will be identified in the thesis and pseudonyms will be used, however you should be aware that only three observations will take place and you may be recognisable to others in the study. If there are more than three volunteers for the observations, random 
selection will be used to choose participants. Your participation in this project will conclude with your completion of the online survey.

Part of the study is looking at the use of technology in mentoring relationships and it would be helpful to have access to your e-portfolio PRT page to explore how technology is being used.

Your participation in all aspects is voluntary and you are under no obligation to agree to be a part of it. Should you wish to withdraw, you may do so without question at any time before the data is analysed. You will be offered a copy of the summary of the study once the project is completed.

Victoria University requires that ethics approval be obtained for research involving human participants. This research has been assessed and approved by Victoria University Faculty of Education Ethics Committee. Responses collected will form the basis of my research project and will be put into a written report on an anonymous basis. Only grouped responses will be presented in this report. All material collected will be kept confidential. No other person besides my supervisor, Dr Kate Thornton, and I will see the surveys or transcripts of discussions. The thesis will be submitted for marking and deposited in the University Library. It is intended that one or more articles will be submitted for publication in scholarly journals. Surveys and transcripts will be destroyed five years after the end of the project.

If you have any questions or would like to receive further information about the project, please contact me (charlieandsarah@xtra.co.nz) or my supervisor, Dr Kate Thornton (kate.thornton@vuw.ac.nz), at the School of Educational Policy and Implementation at Victoria University, PO Box 600, Wellington, phone 4639776.

If you agree to participate, please fill in and sign the consent form, and hand it to Lucy by Friday 22 June 2012.

Kind regards

Sarah Patterson 


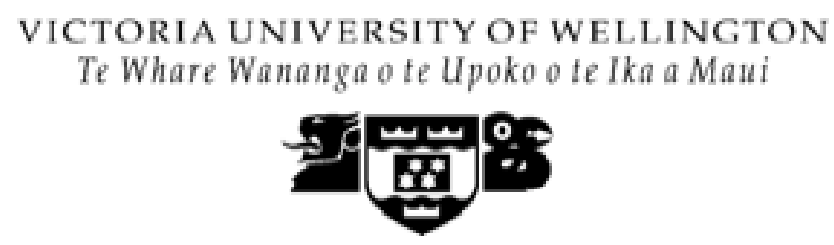

Faculty of Education

Research project: Mentoring beginning teachers within an intermediate setting Consent form for PRTs

[Please mark each box with a tick to indicate agreement, then sign and date this form]

I have been given and have understood an explanation relating to the nature and purpose of this research project. I have had an opportunity to ask questions about it.

I give permission for the researcher to collect data through an online survey.

I give permission for the researcher to collect data through a focus group discussion.

I give permission for the researcher to conduct an observation during a meeting with my PRT/mentor teacher (if applicable).

I give permission for the researcher to have access to my e-portfolio PRT page.

I understand that the data collected will be kept secure. Only the researcher and a supervisor will have access to the data. I also understand that all the data collected will be destroyed 5 years after the conclusion of the study.

I understand that my name will not be revealed in any publication arising from this research, instead pseudonyms will be used. 
I understand that the research may be presented in academic or professional journals.

I understand that I can withdraw from this study without giving a reason up until the conclusion of the data collection.

Name

Signature

Date 
Appendix E

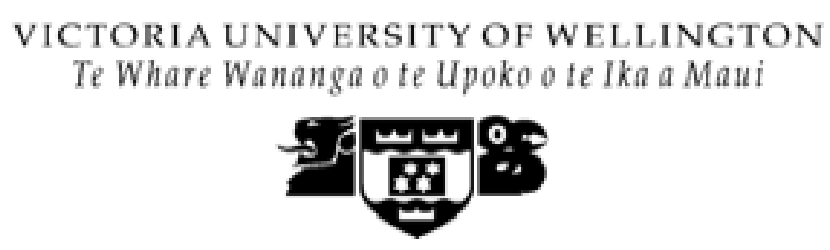

Faculty of Education

Research project: Mentoring beginning teachers within an intermediate setting

Information Sheet for school principal

Researcher: Sarah Patterson

I am wishing to conduct research at NIS around the mentoring of beginning teachers as part of my Masters study. The aim of the project is to evaluate the current state of mentoring practice in relation to the new educative mentoring guidelines and identify areas for improvement. It includes two workshops designed to improve mentoring skills of all teachers.

As part of this research I am seeking the participation of current and past mentor teachers and first, second and third year teachers. Their participation will consist of:

- Completion of an anonymous online survey (approximately 5-10 minutes) for all participants

- Possible focus group session (one hour) for all participants

- Two one-hour workshops focussing on improving mentoring practice

- Observations of three different PRT meetings for current mentor teachers and first and second year teachers who volunteer

- Completion of a second anonymous online survey (approximately 5-10 minutes) for all participants except third year teachers.

A link to the online survey will be emailed out to participants upon receiving the consent form. Participants will be asked to pick a 4-digit number when completing the survey. This is to track the difference between their answers at the start of the study and their answers at the end of the study and in no way identifies them.

It is possible there will be a focus group session to gain clarity around the data received from the initial survey but participants will be informed of this following the initial survey. There will be two one-hour workshops for the mentor teachers designed to improve mentoring practice following the results of the initial survey. These workshops will be conducted during Wednesday morning professional development sessions. I am also asking for volunteers to 
be observed during one PRT meeting. The participants of the observations will not be identified and pseudonyms will be used, however they have been made aware that only 3 observations will take place and they may be recognisable to others in the study. Participation in this project will conclude with the completion of the online survey.

Part of the study is looking at the use of technology in mentoring relationships and PRTs have been asked to give the researcher access to their e-portfolio PRT page to explore how technology is being used.

Participation is voluntary and teachers are under no obligation to agree to be a part of it.

A copy of the study will be offered to the school following its completion.

Victoria University requires that ethics approval be obtained for research involving human participants. Should any participants feel the need to withdraw from the project, they may do so without question at any time before the data is analysed. Responses collected will form the basis of my research project and will be put into a written report on an anonymous basis. Only grouped responses will be presented in this report. All material collected will be kept confidential. No other person besides my supervisor, Dr Kate Thornton, and I will see the surveys or transcripts of discussions. The thesis will be submitted for marking to the School of Educational Policy and deposited in the University Library. It is intended that one or more articles will be submitted for publication in scholarly journals. Surveys and transcripts will be destroyed five years after the end of the project.

If you have any questions or would like to receive further information about the project, please contact me (charlieandsarah@xtra.co.nz) or my supervisor, Dr Kate Thornton (kate.thornton@vuw.ac.nz), at the School of Educational Policy at Victoria University, PO Box 600, Wellington, phone 4639776.

If you intend to allow NIS to participate in this study, please complete and sign the consent form and return to Lucy by Friday 22 June 2012.

Kind regards

Sarah Patterson 
Research project: Mentoring beginning teachers within an intermediate setting Consent form for school principal

[Please mark each box with a tick to indicate agreement, then sign and date this form]

I have been given and have understood an explanation relating to the nature and purpose of this research project. I have had an opportunity to ask questions about it.

I give permission for the researcher to collect data from teachers at NIS.

I understand that the data collected will be kept secure. Only the researcher and a supervisor will have access to the data. I also understand that all the data collected will be destroyed 5 years after the conclusion of the study.

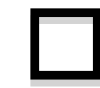

I understand that the research may be presented in academic or professional journals.

I understand that I can withdraw the school from this study without giving a reason up until the conclusion of the data collection.

Name

Signature

Date 


\section{Appendix F}

\section{Survey questions for mentor teachers}

1. Are you currently a mentor teacher? If you are not currently a mentor teacher, please give the reason below and answer the questions based on when you were a mentor.

2. How many years experience do you currently have as a mentor teacher? Under 1 year 1-2 years 3-4 years 5-6 years 7-8 years 9-10 years 11+ Using a scale of $1-5$ where 1 is strongly disagree and 5 is strongly agree please rank how true the following statements are.

3. My PRT sets their own goals.

4. My PRT's goals are co-constructed with me.

5. Meeting and observation times are planned for and kept to.

6. During meetings I spend more time listening to my PRT than talking.

7. I use effective questioning to promote deeper thinking and challenge my PRT's pedagogical beliefs.

8. I use active listening when my PRT speaks.

9. I use evidence to back up my observation feedback.

10. I encourage my PRT to make their own decisions.

11. I have an 'open door' policy and my PRT can approach me outside of scheduled meeting times.

12. I value the knowledge my PRT already has.

13. My PRT believes I am an effective mentor.

14. The PRT programme at NIS is highly effective.

Please write a statement around the following:

15. In what ways does technology assist the mentoring relationship?

16. How might the induction and mentoring programme be improved at NIS? 


\section{Appendix G}

\section{Survey Questions for PRTs}

1. In which year of teaching are you?

Using a scale of 1 - 5 where 1 is strongly disagree and 5 is strongly agree please rank how true the following statements are.

2. Meeting and observation times are planned for and kept to.

3. I set my own goals.

4. Goals are co-constructed with my mentor teacher.

5. During meetings my mentor spends more time listening than talking.

6. My mentor teacher uses active listening when I speak.

7. My mentor teacher uses effective questioning to promote deeper thinking and challenge my pedagogical beliefs.

8. My mentor teacher uses evidence to back up feedback given.

9. I am encouraged to make my own decisions.

10. My mentor teacher has an 'open door' policy and I feel I can approach them outside of scheduled meeting times.

11. My mentor teacher values the knowledge I already have.

12. The PRT programme at NIS is highly effective.

13. I am given adequate support as a PRT.

Please write a statement around the following:

14. In what ways does technology assist the mentoring relationship?

15. How might the induction and mentoring programme be improved at NIS? 